\title{
LEG 156
}

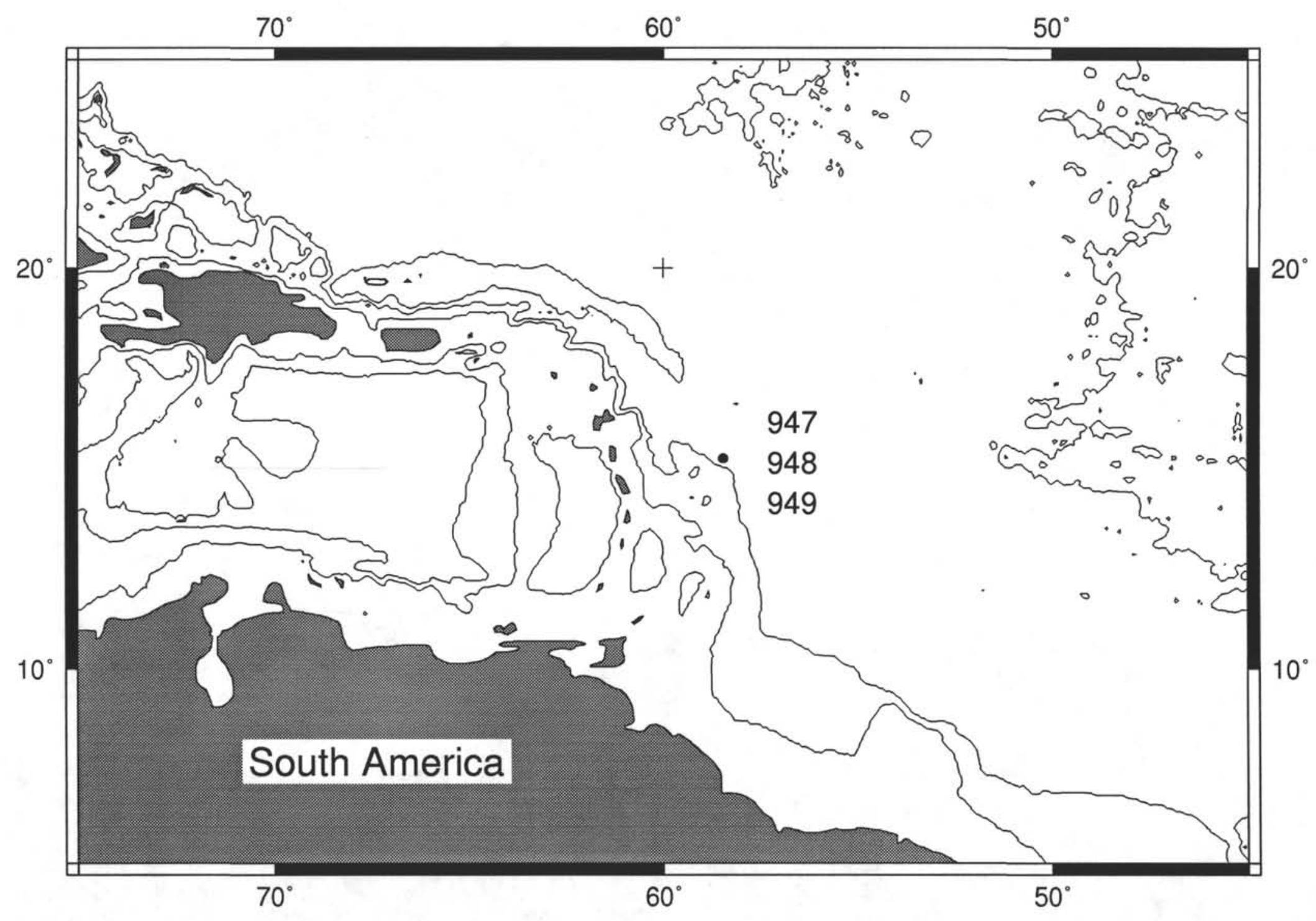




\section{LEG 156}

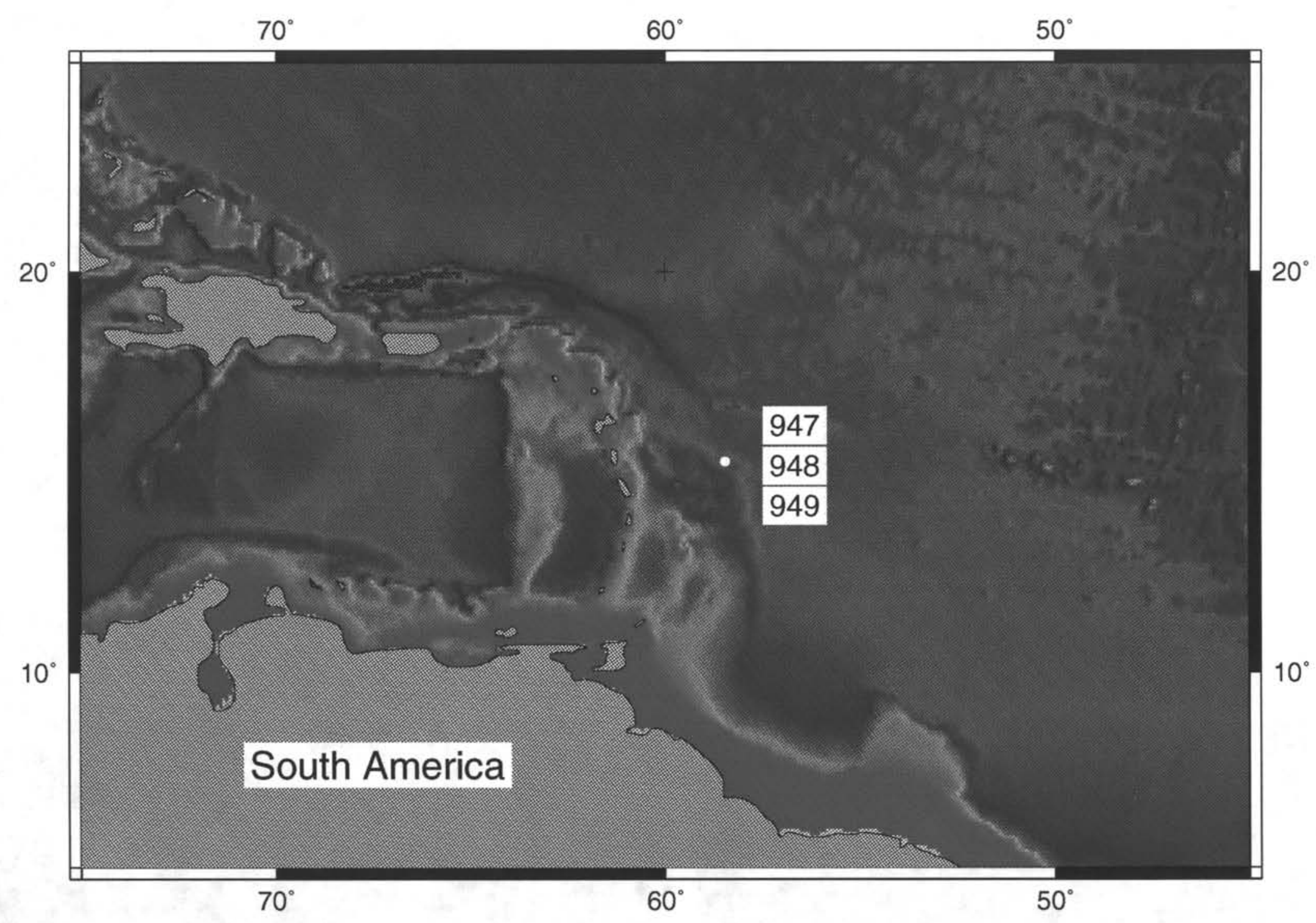




\section{OCEAN DRILLING PROGRAM \\ LEG 156 PRELIMINARY REPORT \\ NORTH BARBADOS RIDGE}

Dr. Thomas H. Shipley Co-Chief Scientist, Leg 156 Institute for Geophysics University of Texas at Austin 8701 North Mopac Boulevard Austin, Texas 78759

U.S.A.
Dr. Yujiro Ogawa

Co-Chief Scientist, Leg 156

Institute of Geoscience

University of Tsukuba

Tsukuba, Ibaraki 305 Japan

Dr. Peter Blum

Staff Scientist, Leg 156

Ocean Drilling Program

Texas A\&M University Research Park

1000 Discovery Drive

College Station, Texas 77845-9547

U.S.A.

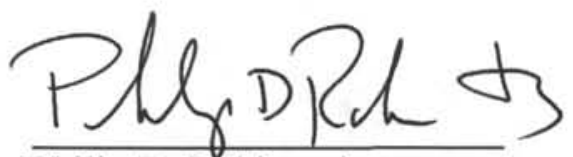

Philip D. Rabinowitz

Director

ODP/TAMU

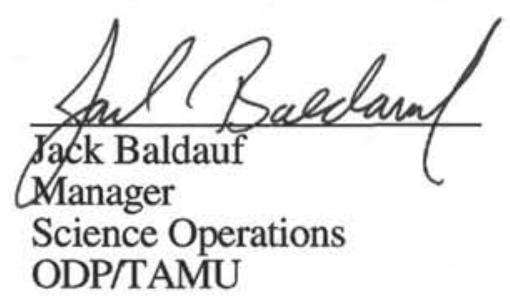


This informal report was prepared from the shipboard files by the scientists who participated in the cruise. The report was assembled under time constraints and is not considered to be a formal publication which incorporates final works or conclusions of the participating scientists. The material contained herein is privileged proprietary information and cannot be used for publication or quotation.

\section{Preliminary Report No. 56}

First Printing 1994

\section{Distribution}

Copies of this publication may be obtained from the Director, Ocean Drilling Program, Texas A\&M University Research Park, 1000 Discovery Drive, College Station, Texas 77845-9547, U.S.A. In some cases, orders for copies may require payment for postage and handling.

\section{D $\underline{I} \underline{\mathrm{S}} \underline{\mathrm{C}} \underline{\mathrm{L}} \underline{\mathrm{A}} \underline{\mathrm{M}} \underline{\mathrm{M}} \underline{\mathrm{R}} \underline{\mathrm{R}}$}

This publication was prepared by the Ocean Drilling Program, Texas A\&M University, as an account of work performed under the international Ocean Drilling Program, which is managed by Joint Oceanographic Institutions, Inc., under contract with the National Science Foundation. Funding for the program is provided by the following agencies:

Canada/Australia Consortium for the Ocean Drilling Program

Deutsche Forschungsgemeinschaft (Federal Republic of Germany)

Institut Français de Recherche pour l'Exploitation de la Mer (France)

Ocean Research Institute of the University of Tokyo (Japan)

National Science Foundation (United States)

Natural Environment Research Council (United Kingdom)

European Science Foundation Consortium for the Ocean Drilling Program (Belgium, Denmark, Finland, Greece, Iceland, Italy, The Netherlands, Norway, Spain, Sweden, Switzerland, and Turkey)

Any opinions, findings and conclusions or recommendations expressed in this publication are those of the author(s) and do not necessarily reflect the views of the National Science Foundation, the participating agencies, Joint Oceanographic Institutions, Inc., Texas A\&M University, or Texas A\&M Research Foundation. 
SCIENTIFIC REPORT 
Leg 156

Preliminary Report

Page 4

The following scientists were aboard JOIDES Resolution for Leg 156 of the Ocean Drilling Program:

Thomas H. Shipley, Co-Chief Scientist (Institute for Geophysics, University of Texas, 8701 North Mopac Boulevard, Austin, Texas 78759, U.S.A.; E-mail: tom@utig.ig.utexas.edu)

Yujiro Ogawa, Co-Chief Scientist (Institute of Geoscience, University of Tsukuba, Tsukuba, Ibaraki 305, Japan; E-mail: yogawa@arsia.geo.tsukuba.ac.jp)

Peter Blum, ODP Staff Scientist (TAMU Research Park, Ocean Drilling Program, 1000 Discovery Drive, College Station, Texas 77845-9547, U.S.A.; E-mail: blum@nelson.tamu.edu) Juichiro Ashi (Geological Institute, University of Tokyo, 7-3-1 Hongo, Bunkyo, Tokyo 113, Japan; E-mail: ashi@tsunami.geol.s.u-tokyo.ac.jp)

Warner Brückmann (GEOMAR, Research Center for Marine Geosciences, Wischhofstrasse 1-3, Building 4, D-24148 Kiel, Federal Republic of Germany; E-mail: ngm12@rz.unikiel.d400.de)

Frank Filice (Lamont-Doherty Earth Observatory, Borehole Research Group, Palisades, New York 10964, U.S.A.; E-mail: filice@ldeo.columbia.edu)

Andrew Fisher (Department of Geological Sciences and Indiana Geological Survey, Indiana

University, 611 N. Walnut Grove, Bloomington, Indiana 47405, U.S.A.; E-mail:

fisher@terra.geology.indiana.edu)

Dave Goldberg (Borehole Research Group, Lamont-Doherty Earth Observatory, Palisades, New

York 10964, U.S.A.; E-mail: goldberg@ldeo.columbia.edu)

Pierre Henry (Laboratoire de Géologie, de l'École Normale Supérieure, URA 1316 du C.N.R.S., 24 rue Lhomond, 75231 Paris Cedex 05, France; E-mail: henery @geologie.ens.fr)

Bernard Housen (Department of Geological Sciences, University of Michigan, 1006 C.C. Little Building, Ann Arbor, Michigan 48109-1063, U.S.A.; E-mail: bernard.a.housen @um.cc.umich.edu)

María-José Jurado (Instituto de Ciencias de la Terra (Jaume Almera) C. SIC, Martí i Franqués s/n, 08028, Barcelona, Spain; E-mail: mjjurado@u.ija.csic.es)

Miriam Kastner (Geological Research Division-0212, Scripps Institution of Oceanography, University of California, San Diego, 9500 Gilman Drive, La Jolla, California 92093-0212, U.S.A.; E-mail: mkastner@ucsd.edu)

Pierre Labaume (Géofluides, Bassins, Eau, Université Montpellier II, 34095 Montpellier Cedex 5, France)

Troels Laier (Geological Survey of Denmark, Thoravej 8, DK-2400 Copenhagen, Denmark) 
Leg 156

Preliminary Report

Page 5

Evan C. Leitch (Department of Applied Geology, University of Technology, Sydney, P.O. Box

123, Broadway, NSW 2007, Australia; E-mail: eleitch@acacia.itd.uts.edu)

Alex J. Maltman (Institute of Earth Studies, University of Wales, Aberystwyth, Wales SY23 3DB, United Kingdom; E-mail: ajm@aber.ac.uk)

Audrey Meyer (Mira Costa College, P.O. Box 68, Palomar Mountain, California 92060, U.S.A.;

E-mail: audreym@odpwcr.ucsd.edu)

Gregory F. Moore (Department of Geology and Geophysics, University of Hawaii, 2525 Correa

Road, Honolulu, Hawaii 96822, U.S.A.; E-mail: moore@elepaio.soest.hawaii.edu)

J. Casey Moore (Earth Sciences Board, University of California, Santa Cruz, Santa Cruz,

California 95064, U.S.A.; E-mail: casey@java.ucsc.edu)

Sheila Peacock (School of Earth Sciences, University of Birmingham, Edgbaston, Birmingham

B15 2TT, United Kingdom; E-mail: peacocks@es5.ers.bham.ac.uk)

Alain Rabaute (Laboratoire de Géochimie Isotopique CC 66, Université Montpellier II, 34095

Montpellier Cedex 5, France; E-mail: rabaute@dstu.univ-montp2.fr)

Torsten H. Steiger (Institut für Paläontologie und hist Geologie, Richard-Wagner-Strasse 10, 80333 München, Federal Republic of Germany)

Harold J. Tobin (Earth Sciences Board, University of California, Santa Cruz, Santa Cruz, California 95064, U.S.A.; E-mail: harold@java.ucsc.edu)

Michael B. Underwood (Department of Geological Sciences, 101 Geology Building, University of Missouri, Columbia, Missouri 65211, U.S.A.; E-mail: geoscmbu@mizzou1.missouri.edu)

Yan Xu (Department of Geology, Florida State University, Tallahassee, Florida 32306-3026, U.S.A.; E-mail: xu@geomag.gly.fsu.edu)

Hezhu Yin (Lamont-Doherty Earth Observatory, Borehole Research Group, Palisades, New York 10964, U.S.A.)

Yan Zheng (Lamont-Doherty Earth Observatory, Palisades, New York 10964, U.S.A.; E-mail: yzheng@lamont.ldgo.columbia.edu)

Gretchen Zwart (Earth Sciences Department, University of California, Santa Cruz, Santa Cruz, California 95064, U.S.A.; E-mail: gretchen@java.ucsc.edu) 
Leg 156

Preliminary Report

Page 7

\begin{abstract}
Leg 156 investigated temporal and spatial scales of fluid flow, the role of faults in fluid transport, and the relationship between mechanical state and seismicity in the northern Barbados Ridge accretionary prism. The strategy was to drill into areas of strikingly different polarity and amplitude of the décollement reflection, revealed by recently acquired, three-dimensional seismic data and interpreted as areas of varying fluid content and/or fluid migration paths within the décollement.
\end{abstract}

Eight holes were drilled at Sites 947, 948, and 949, located $6 \mathrm{~km}, 4 \mathrm{~km}$, and $2 \mathrm{~km}$ west of the thrust front, respectively. Site 948 is located in an area of positive polarity, inferred to have normal porosity, decreasing with depth, from the seismic data. Sites 947 and 949 investigated portions of the décollement zone that have negative-polarity seismic reflections thought to represent highporosity zones of high fluid pressure. Our scientific objectives required an ambitious operational program including cased-hole installations, downhole measurements, and emplacement of longterm borehole observatories in a region known for its drilling and downhole logging difficulties due to unstable hole conditions.

Logging-while-drilling (LWD) at Sites 947 and 948 at the beginning of the leg recorded the most complete resistivity, natural gamma-ray, density, and neutron porosity logs ever obtained from the notoriously unstable accretionary-prism environment. At Hole 948A, logging data show that the positive-polarity reflection results from an increase in velocity and bulk density at a lithologic change within the décollement at about $515 \mathrm{~m}$. However, the LWD data also reveal two thin zones of high ( $66 \%$ and $60 \%$ ) porosity at 505 and $514 \mathrm{~m}$; these two thin zones are below the limits of seismic resolution. At Hole 947A, just above the décollement from 520 to $535 \mathrm{~m}$ and in the zone where the drill string became stuck, the porosity is also anomalously high (about 70\%). Synthetic seismogram modeling using the logging data creates a negative-polarity seismic reflection at this level, which is also present on the seismic data. The zone is interpreted as a listric thrust rising off the décollement. The logging results at Sites 947 and 948 suggest that high fluid pressure of differing magnitude may exist all along the décollement zone.

The décollement zone was well defined by coring at Site 948. It includes lower to middle Miocene claystone, underlain by lower Miocene and upper Oligocene variegated claystones, with muddy turbidites and redeposited chalk. The 31-m-thick fault zone exhibits scaly fabric, fracture 
Leg 156

Preliminary Report

Page 8

networks, and stratal disruptions interleaved with intact intervals of sediment. Coring at Site 949 recovered insufficient core to define the extent of the décollement. The accretionary-prism sections cored at Sites 948 and 949 are permeated at distinct levels by fluids having a salinity lower than that of seawater. The most distinct low- $\mathrm{Cl}$ fluid interval (about $18 \%$ less than seawater) was intercepted at Site 948 at the top of the décollement. Although less intensive, three low-Cl intervals intercepted at Site 949 correlate with postulated thrust faults. Thus, the geochemical-depth profiles are consistent with active focused fluid flow along conduits from greater depth.

In Holes 948D and 949C, casing was set from the seafloor through the décollement. Casing within the décollement zones was perforated and screened to allow hydrologic communication between the cased hole and the décollement. This allowed successful packer measurements of fluid pressure and permeability in the décollement zone. Initial analysis of packer results from Site 948 suggests that pressure may have increased to $90 \%$ of lithostatic during the period the screened section was isolated, providing tantalizing indications of high in situ fluid pressure. Confirmation however can only follow shore-based work.

Vertical seismic profiles were collected in the cased holes to calibrate the seismic reflection models. An offset VSP at Site 949 used 18 bottom-shot explosions to determine shear-wave polarization to study stress orientation and structural fabrics. Holes 948D and 949C were finally instrumented with a French-designed and a U.S.-Canadian-designed temperature and pressure sensor string, respectively, and at Site 949 with a U.S.-designed continuous fluid sampler. Prior to instrument deployment, Hole 948D had to be "killed" with heavy mud to stop sediment infill and outflow of sediment-laden water from the reentry cone, whereas sediment infill in Hole 949C was stopped by means of a mechanical plug at the bottom of the casing. The instruments deployed in these holes are designed to collect data over the next few years to assess the episodicity of fluid behavior. A submersible expedition in 1995 will collect pressure and temperature data from the sensors and conduct hydrologic testing in the sealed holes. 
Leg 156

Preliminary Report

Page 9

\section{INTRODUCTION}

The importance of fluids in accretionary-prism tectonics was a special topic at a NATO-sponsored workshop in 1989 and spurred innovative experiments and new techniques (Langseth and Moore, 1990). Fluids critically affect the structural development and architecture of accretionary prisms and their potential evolution into mountain belts (e.g., Hubbert and Rubey, 1959). Structural and geochemical studies of recovered samples from Barbados and elsewhere attest to multiple fluidflow events and for the importance of both intergranular and fracture permeability (e.g., Moore and Vrolijk, 1992; Knipe et al., 1991; Moore et al., 1982). Yet we have not been able to tie these observations to even the most fundamental temporal and spatial scales to validate dynamic flow models (e.g., Screaton et al., 1990; Shi and Wang, 1988). On Leg 156, our objective was to combine both in situ measurements of permeability and fluid pressures, long-term monitoring of temperature and pressure, and fluid chemistry and structural fabric studies in an integrated program. This experiment is an important and necessary step in evaluating the role of faults in fluid transport, episodicity of fluid flow, and the relationship to seismicity. Understanding the fate of subducted and accreted fluids will also contribute to geochemical cycle definition (Kastner et al., 1991). This program is a logical step in advancing the technological and drilling techniques needed in this environment.

\section{Site 947}

Site 947 (proposed Site NBR-3) was positioned, in part, to explore the high-amplitude negativepolarity fault reflection for comparison to the seismic character at Site 948, where the décollement exhibits positive polarity (Figs. 1, 2, and 3). For the first time in the history of ODP, we deployed a logging-while-drilling (LWD) system. This logging system was necessary because hole instability had prevented wireline logging on both Leg 78A and Leg 110 . The LWD program at Hole 947 A obtained logs from the seafloor to 574 mbsf. Drilling conditions stopped the LWD about $60 \mathrm{~m}$ above the seismically identified décollement in a fault splay.

The principal results at this site are from interpretation of the logging data. The primary logs include dual resistivity with natural gamma-ray spectroscopy and compensated density-neutron. Because of the high rates of penetration the total gamma-ray counts are of good quality, but the 
Leg 156

Preliminary Report

Page 10

spectral data are not. Neutron porosity logs are noisy and show significantly higher values than calculated from the density log. Without cores, the logging data interpretations use "electrofacies" (boundaries in log character, internal curve shape). Seven identified log "units" define subtle depositional variations and commonly have sharp boundaries related to compaction trend offsets. Four primary intervals having a downhole decrease in density relate to two different processes. Two intervals may represent discrete thrust packages bringing higher density sections over lower density ones, given the sharp nature of the boundaries. Two other intervals are more diffuse at their boundaries and could result from natural lithologic variations or faulting; whether due to faulting or lithologic variations, the density trend reversals indicate elevated pore pressures necessary to arrest compaction.

Near the base of the hole the density falls to low values which, when using Site 671 grain densities, yields a porosity of $70 \%$, essentially the same value found at the surface and at the incipient décollement at Site 672 . The high porosity at this depth must be supported by high fluid pressures.

We planned to return to Site 947 after completing Site 948 to core, obtain wireline logs, and carry out VSP, packer and CORK experiments. Unfortunately, after completion of Site 948 there was insufficient time to return and complete a full operational and experimental program. In its place Site 949 examines a similar objective at a shallower sub-bottom depth. Site 947 for now consists of logs and no cores, an unusual event in scientific ocean drilling.

\section{Site 948}

Site 948 (proposed Site NBR-2) calibrates the positive-polarity seismic signature of the décollement (Fig. 3). It is also as close as we could navigate to Hole 671B, which penetrated the 40-m-thick décollement and $151 \mathrm{~m}$ into the underthrust section on ODP Leg 110 (Fig. 2). Hole $948 \mathrm{~A}$ was dedicated to logging. Hole $948 \mathrm{~B}$ was a jet-in test site. Hole $948 \mathrm{C}$ was dedicated to interval coring and logging. Hole 948D, $200 \mathrm{~m}$ south of Holes 948A and 948C, was cased to 535.3 mbsf for special experiments. 
Leg 156

Preliminary Report

Page 11

At Hole 948A we collected logs using logging-while-drilling (LWD) technology, which is a more effective technique than wireline logging in unstable formations such as accretionary prisms. The logging provided compensated dual resistivity, natural gamma-ray (CDR tool), compensated density neutron, neutron porosity, and gamma-ray ( $\mathrm{CDN}$ tool) measurements from 0 to $582 \mathrm{mbsf}$. Drilling conditions remained very good to about $515 \mathrm{mbsf}$, when circulation pressures increased. The section logged included the décollement zone, which was observed in Hole 671B at about 500 to $540 \mathrm{mbsf}$ and in Hole $948 \mathrm{C}$ at 498 to $529 \mathrm{mbsf}$.

The resistivity, gamma-ray, and bulk-density logs correlate with the physical properties measured on Site 671 cores. An abrupt decrease in density below a fault at 132 mbsf marks the overthrusting of tectonic packages recorded at Site 671. This same trend is observed in the resistivity log. An increase in total gamma-ray count from 315 to $380 \mathrm{mbsf}$ is related to a distinct break in the relative abundances of carbonate and clay minerals, where carbonate is absent and the clay-mineral content (which contains a larger portion of radioactive elements) increases.

The LWD logs show pronounced changes across the décollement. Resistivity drops, and bulk density increases. Gamma-ray and resistivity changes occur over a $10-\mathrm{m}$ interval corresponding to the middle of the structurally defined décollement. These differences primarily reflect the change in lithology and clay mineralogy at about 514 mbsf. The increase in gamma ray in the underthrust section must in part be due to an increase in illite (potassium-rich) observed at Sites 671 and 948.

Within the structurally defined décollement there are two low-density spikes at 505 and $514 \mathrm{mbsf}$. Assuming these are not related to grain-density changes, they reflect porosities of $66 \%$ and $60 \%$, in contrast to surrounding sections with 55\% to $47 \%$ porosity. The second spike is coincident with the lithologic boundary and spans a 3-m interval. Overall, such changes could reflect fault-zone dilation across thin zones that are below the resolution of the 3-D seismic data.

A substantial decrease in density from about $2.0 \mathrm{Mg} / \mathrm{m}^{3}$ at $395 \mathrm{mbsf}$ to $1.8 \mathrm{Mg} / \mathrm{m}^{3}$ at $500 \mathrm{mbsf}$, just above the décollement, is similar to density trends in the interval from 100 to $200 \mathrm{mbsf}$. Given the fairly uniform lithologies, this zone must be related to significant undercompaction and high fluid pressures. This zone coincides with the lowest pore-water chlorinity. 
Leg 156

Preliminary Report

Page 12

LWD is unique in logging the upper hundred meters of the hole; this section cannot be studied by wireline logs because of the necessity to leave some pipe in the hole. The shallow LWD logs will specify the physical property evolution related to both compaction and the unique tectonohydrologic conditions of this environment.

Hole $948 \mathrm{C}$ began with a mud-line core that recovered $10.1 \mathrm{~m}$ of Pleistocene brown clay with nannofossils. The section includes abundant ash layers. The hole was drilled without coring from 9.5 to 420.8 mbsf. Temperature measurements at $65,103,200,248,327$, and 422 mbsf, when added to Site 671 data, yielded gradients from $92^{\circ}$ to $97^{\circ} \mathrm{C} / \mathrm{km}$ in the upper part of the hole, to about $66^{\circ} \mathrm{C} / \mathrm{km}$ in the lower part of the section. Coring at Hole $948 \mathrm{C}$ resumed with Cores 156948C-2X to $-19 \mathrm{X}$ (420.8 to $592.0 \mathrm{mbsf}$ ), with $95 \%$ recovery. Based on the seismic reflection geometry and seafloor depths, the depth to the décollement from the seafloor is $6.5 \mathrm{~m}$ deeper in the $\mathrm{A}$ and $\mathrm{C}$ holes than in the $\mathrm{D}$ hole.

There is a major lithologic boundary at 513.9 mbsf. The lower unit (Unit III) is early Miocene and late Oligocene in age and consists of greenish-gray claystone as a background lithology, with rhythmic graded interbeds of gray turbidite claystone and nannofossil chalk. The uppermost part of this unit, from 513.9 to $523.8 \mathrm{mbsf}$, comprises gray-to-brown banded variegated claystones. The base of the overlying unit starts as a grayish-brown claystone from 507.7 to $513.9 \mathrm{mbsf}$; this subunit is overlain by distinctive pinkish-gray/brownish-gray radiolarian claystone of early to middle Miocene age from 498.1 to $507.7 \mathrm{~m}$. Above are subunits of undetermined to late Miocene age, including gray claystone with nannofossils, variegated claystone with thin interbeds of tuff and altered volcanic ash, and gray to olive claystone. The bulk mineral content is highly variable in the section below the décollement, largely in response to fluctuations in the carbonate content which is mostly partitioned into the nannofossil-rich turbidites. Plagioclase decreases to trace abundances below the décollement. In the cored interval above the décollement the relative weight percentage of clay minerals is consistently about $60 \%$ until it increases to about $70 \%$ in the décollement, between 498 and 514 mbsf. Quartz content is uniform throughout.

From 498 to 529 mbsf, low-dip zones of semi-penetrative scaly fabric interleaved with zones of fracture networks or stratal disruption, and structurally intact sediments, define the décollement zone. The fault-zone boundary is gradational over several meters at the bottom but is sharp at the top. The major lithologic change near the middle of the fault zone at 513.9 mbsf marks a boundary 
Leg 156

Preliminary Report

Page 13

between more brittle deformation above and more ductile deformation below. There are mineral veins in the upper half and higher in the section, but not in the lower half of the fault zone. Discrete zones of shear fabric are well developed in both the upper and lower lithologies. Bedding dips define two domains through the cored interval, with moderate to steep dips above the décollement, and shallow to subhorizontal dips below. Several smaller shear zones occur both above and below the décollement; some, such as one at 423 mbsf, exhibit fabric-parallel rhodochrosite veins and tight folding on a centimeter scale. Mineral preferred orientation fabrics were determined by shipboard study of anisotropy of magnetic susceptibility (AMS). Above the décollement the AMS results indicate horizontal, east-west shortening in the prism. Just above the décollement the AMS orientation gradually changes to a geometry consistent with a vertical compaction fabric. Below the décollement the amount of vertical compaction indicated by AMS is more pronounced.

Organic carbon in the accretionary prism and décollement is less than $0.05 \%$ and varies between 0 and $1.83 \%$ in the underthrust section. Methane concentrations were very low, the highest being 44 ppm just above the décollement. Very low concentrations of ethane and propane were found with methane/ethane ratios of 20 to 60 , suggesting thermogenic origin of some of the gas. However, shore-based isotopic analyses are necessary to confirm any thermogenic origins. Interstitial water samples indicate dilution by fresh water. The chemical concentration depth profiles exhibit both diffusive and advective characteristics. Focused chloride dilution (about $18 \%$ seawater dilution) is observed at the top of the décollement. It coincides with the methane concentration maximum of 44 ppm of methane. While the shapes of the curves of chloride and methane are similar to those observed at Site 671, their magnitudes are distinctly different. The concentration-depth profiles of the analyzed major and minor elements are consistent with mostly up-dip fluid flow.

Physical property data provide correlation and calibration of the LWD data and a comprehensive downhole profile through the fault zone. An offset in most downhole profiles occurs within the décollement zone. This is the result of a major lithologic change. Below $508 \mathrm{mbsf}$ a sharp offset to higher densities is observed. Compressional-wave velocities decrease somewhat, but the overall impedance change is a positive contrast, similar to the seismic data. Shear-wave velocities measured in discrete samples are low, probably indicative of the low strength of these sediments.

With the use of the (conical) side-entry sub system, wireline logs of sonic, spectral gamma ray, and density were recorded in Hole $948 \mathrm{C}$ to a total depth of $575 \mathrm{mbsf}$, well below the décollement. 
Leg 156

Preliminary Report

Page 14

Unstable hole conditions prior to logging required frequent pumping to remove obstacles, especially in the vicinity of the décollement. High wireline tensions during logging of the bottom $60 \mathrm{~m}$ reflect hole constrictions and generally unstable hole conditions. Sonic logs show only a small downhole increase in velocity at the décollement. The caliper log indicates widely variable hole diameters that degrade the logging data. The poor hole conditions prohibited multiple logging runs.

Hole 948D was drilled for the long-term borehole observatory (CORK) and other downhole experiments. A triple-string casing program was designed to ensure hole stability for the experiments and placement of a screened section across the fault. Cement was pumped down to the bottom of the second casing shoe at 476 mbsf to assure hydrologic isolation of the formations above the décollement for subsequent packer and CORK monitoring. After the second casing placement, a cement bond $\log$ (CBL) and a vertical seismic profile (VSP) were run. There was good bonding in the lowermost 25 to $30 \mathrm{~m}$ of the logged hole, plus another $10 \mathrm{~m}$ estimated below the lowest log depth hydrologically isolating the lower part of the hole from the upper part. The VSP extends from about 470 up to about 96 mbsf within the cased hole using magnetically clamped geophones. The data confirm the results from the cement-bond log, showing the best records near the base of the hole, less than $50 \mathrm{~m}$ above the décollement. Uphole the records are more noisy, but shipboard processing shows that the data are of good quality throughout the logged interval. The velocity estimated from the VSP is generally higher than the laboratory measurements or the sonic logging data.

Screened casing was set through the fault zone from 480.7 to 522.6 mbsf. A series of packer tests was run with a drill-string packer set in the casing above the screened interval. First, a series of "negative" pulse and flow tests exposed the isolated formation to hydrostatic pressure and monitored its recovery. A positive pulse test showed a rapid pressure rise, then a small initial decay, and then remained elevated and constant for the next $55 \mathrm{~min}$. Three more positive pulse tests were run, and then three positive, constant flow tests at three different pumping rates, each including shut-in and measurement of recovery at the end. The packer recorded pressure increases to near lithostatic values during the time the well was shut in. However, these data require substantial analysis and evaluation, given the significant formation disturbance during the setting of casing. 
Leg 156

Preliminary Report

Page 15

Lastly, we deployed the temperature and pressure sensor string with the data logger and the borehole seal (CORK) assembly. Our efforts were hampered by sediment filling the casing from below and flow out the reentry cone at the sealoor. Cleaning attempts could not keep up with the sediment filling the casing. We stopped the sediment inflow by filling the hole with a column of $1.66 \mathrm{Mg} / \mathrm{m}^{3}$ mixed barite and bentonite mud from 538 to about $65 \mathrm{mbsf}$. We do not know if the screen was damaged (allowing inflow through the perforations in the casing) or if sediment was flowing up from the bottom of the open casing. We then deployed the IFREMER data logger with 20 temperature sensors and 3 pressure sensors. Pressure sensors are at 8, 479, and 509 mbsf.

The CORK was then seated but would not latch, leaving the weight of the CORK (and its associated pipe) to hold the seal in place. This weight is equivalent to the piston force that will be acting on the CORK if the fluid pressure below it reaches about $1 \mathrm{MPa}(142 \mathrm{psi})$. The radical use of heavy mud to prevent the formation from flowing into the casing will undoubtedly further modify the hydrologic system. The failure of the CORK to latch will also potentially be a problem, which may at least in part be accommodated by the heavy mud and multiple pressure sensors. The deepest pressure sensor, within the screened zone, should come to equilibrium with the formation fluid pressure, provided that it does not become hydraulically isolated from the surrounding formation.

Using the preliminary estimates of fluid density and of the mud volume, the column of mud will exert a force of probably not more than $2.8 \mathrm{MPa}(400 \mathrm{psi})$ at the depth of the center of the screen. Combined with the CORK weight, the total CORK and mud system might balance $3.8 \mathrm{MPa}$. The calculated lithostatic load, which should be the maximum possible overpressure, is estimated from the LWD density log to be $4.0 \mathrm{MPa}(575 \mathrm{psi}$ ) at the screen. (These numbers are rough, tentative estimates.) If the CORK should vent during the next year, we may be able to latch it during planned submersible work.

\section{Site 949}

Site 949 (proposed Site NBR-7) was chosen to investigate fault properties associated with the reversed-polarity seismic signature of the décollement. Site 949 is located where the overlying accretionary prism is thinner, and the amplitude of the negative-polarity reflection is not as high as 
Leg 156

Preliminary Report

Page 16

at Site 947 (Figs. 2 and 4). Seismic data define a shallow dipping series of splay faults at about 150 to $225 \mathrm{mbsf}$, cutting off near-horizontal reflections at about $275 \mathrm{mbsf}$ and deeper, and the main décollement at $375 \mathrm{mbsf}$, marked by a reversed-polarity reflection. At $425 \mathrm{mbsf}$ is another reversed-polarity reflection, thought to be either an incipient fault or a stratigraphic boundary.

Hole 949A (line 738, CDP 1227) consists of a mud-line core taken to determine water depth and was followed by a jetting test to determine the first casing point. The core contained lower Pleistocene gray clay with nannofossils. We then offset $125 \mathrm{~m}$ south and $30 \mathrm{~m}$ east to drill Hole 949B (line 733, CDP 1229), which was the prime coring site. Coring started at $244.1 \mathrm{~m}$ in upper Miocene gray claystone with nannofossils but recovered only $40 \%$. Hole 949C (line 737, CDP 1228) was dedicated to the casing, downhole experiments, and emplacement of a sensor string and the CORK. We again cored the interval below the second casing point, from 401.0 to $463.8 \mathrm{~m}$, with the RCB system to obtain more samples from the critical interval of the fault, but recovered only $4 \%$ of the cored interval.

The sedimentology deduced from the limited recovery is similar to that of Site 948 . The poor recovery precludes any detailed comparison with other sites cored in this area on Leg 78A or Leg 110. Even so, the basic stratigraphy can be reconstructed using Site 948 for reference.

A stratigraphic inversion indicates that a thrust fault displaces the upper part of the cored section by a significant amount. Early Miocene radiolarians in a pale yellowish brown claystone occur at about $400 \mathrm{~m}$, in the same core as some scaly fabric, and similar to the décollement association at other sites. Examples of the underthrust brownish gray to greenish gray claystone, with interbeds of siltstone turbidites and remobilized nannofossil chalks, occur in the lower part of the cored interval.

Only two cores yielded sediment material in the presumed décollement zone; the lower one contains the lithologic boundary that occurs within the décollement at Site 948. Deformation structures are similar to those from Site 948, including inclined bedding, core-scale faults, mineralized veins, sediment-filled veins, brecciated zones and fracture networks, stratal disruptions, and scaly fabric. Scaly zones are narrower, and the overall intensity of deformation is weaker, more diffuse, and more widely spaced than at Site 948 . Anisotropic magnetic susceptibility mineral fabrics show a distinct difference in orientation of principal strains between the prism and décollement zone. 
Leg 156

Preliminary Report

Page 17

Headspace gas analysis showed that methane concentrations were below $20 \mathrm{ppm}$ by volume and did not show any trend with depth. Trace quantities of ethane and occasionally propane were found, the methane to ethane ratio being between 20 and 200. Organic carbon content is very low, mostly below $0.2 \%$, although slightly higher in the siltstone turbidites.

Chloride concentration-depth profiles indicate that the cored section is diluted by fresh water. Three distinct zones of low chloride concentration are located at about 290, 360, and 425 mbsf. Two are within the prism, and the other is within the décollement zone. Reversals in most concentrationprofiles from about 270 to 350 mbsf suggest vertical displacement of about $80 \mathrm{~m}$. As little diffusion is observed across the inferred thrust within this interval, it has a maximum age of about 35,000 years.

Four WSTP measurements were made in the cored interval of Hole 949B, at 265, 313, 351, and $458 \mathrm{mbsf}$. The results indicate a fairly linear thermal gradient of about $80^{\circ} \mathrm{C} / \mathrm{km}$, with a bottomhole temperature of $39^{\circ} \mathrm{C}$ at $458 \mathrm{~m}$, suggesting that heat flow is not constant with depth. Paleomagnetic data, primarily bulk-susceptibility variations downhole, follow the Site 948 trends and help define the transition into the décollement. Physical properties data for Holes 949B and C are sparse, and thus downhole profiles are incomplete. Specific relationships between observed reflections and their possible physical cause remain uncertain. The increase in velocity and density across the lithologic boundary, for example, does not explain the negative-polarity reflection observed here and correlated seaward into the basin. The physical property data will serve as a background for the evaluation of thermal and chemical information gained from the long-term measurements in the CORK hole. The data will also add to the general data sets collected on Leg 156 and on Legs 78A and 110.

The second string of casing was placed from near the seafloor to just above the décollement, and the section was cemented to provide hydrologic isolation between the overlying section and the décollement. A cement-bond log indicated that the lowermost $40 \mathrm{~m}$ of the second casing string is well bonded, providing a hydrologic seal from the formations above.

A shear-wave vertical seismic profiling (VSP) experiment used explosive charges on the seafloor around Hole 949C. Eighteen shots were recorded at two intervals to observe shear-wave velocities and polarizations that relate to deformation fabric alignment. A conventional air-gun VSP followed, 
Leg 156

Preliminary Report

Page 18

and the resulting velocity estimates and images confirmed our depth estimates within the borehole relative to the seismic reflection data. As at Site 948 , velocities are about $2 \%$ higher than values used in the original three-dimensional seismic migration and depth conversion, and the velocities decrease just above the décollement.

The final casing string comprised a 54-m-long perforated and screened section above a 14-m unperforated section. Prior to reentering to set this casing, turbid water was observed filling the reentry cone, a situation similar to that encountered at Site 948, and suggested some flow out of the borehole. During two attempts to set the third casing string, sediment fill was found inside the second casing string. This fill was circulated out of the hole, and the third casing string was latched. Next, we tried to use a plug to close the bottom of the casing but could not advance past a spot about $54 \mathrm{~m}$ up from the bottom. The casing plug was modified to improve circulation and was redeployed and set about $3 \mathrm{~m}$ above the bottom of the casing.

Next, the packer was used to perform a series of formation pulse and flow tests to measure hydrologic characteristics at the décollement. Preliminary analysis suggests modest overpressures, less than the pressures recorded at Site 948. This result is consistent with the more subdued evidence for flow and casing filling at this site. A second VSP run in the third casing string followed the packer experiment.

Finally, a string of 10 thermistors and 2 pressure transducers, associated data logger, and a mechanical continuous fluid sampler (MCFS), attached to the sensor string and driven by an osmotic pump, was deployed in Hole 949C. The hole was then sealed with the CORK. Pressure and temperature will be monitored and fluid samples collected for 2 years.

The décollement zone depth is not well defined but is between 380 to $433 \mathrm{mbsf}$. The detailed lithostratigraphy and structural geology are not precisely known because of poor core recovery. Deformation structures are similar to those at Site 948 but are weaker in intensity, as are geochemical indications of fluid flow. The less well-defined décollement and evidence of less intense strain are probably related to the location of the sites only about $2 \mathrm{~km}$ from the thrust front. We did not have time to log this site, but the VSP provides direct correlation of the seismic data to the hole. Detailed velocity data also show a decrease in the 40-m interval above the décollement, suggesting density trends similar to those observed at the other sites. As at Site 948, we observed 
fluid flow out of the reentry cone and sediment infilling of the casing, which made operations challenging. The packer data are suggestive of overpressure within the décollement, but lower than at Site 948 . Further analysis is necessary to confirm these values and to make estimates of bulk permeability. The CORK measurements will provide other estimates of in situ conditions and monitor for a longer period changes in fluid properties.

\section{SUMMARY AND CONCLUSIONS}

ODP Leg 156 logged, cored, cased, and instrumented the major plate-boundary fault (décollement) beneath the northern Barbados Ridge accretionary prism. Site 948 drilling penetrated an area characterized by positive polarity seismic amplitudes on a map derived from three-dimensional seismic data, whereas operations at Sites 947 and 948 investigated portions of the décollement zone that have negative-polarity seismic reflections.

Leg 156 operations, geared to achieve ambitious scientific goals, represented a new era of scientific ocean drilling.This included an impressive set of techniques either rarely used before, not used to this extent before, or used for the first time

1. Logging-while-drilling (LWD), employed for the first time in the ODP, recorded complete logs from the accretionary prism at Sites 947 and 948 . At Site 948 , the logs represent the first of their kind across a major plate boundary.

2. Casing strings up to more than $500 \mathrm{~m}$ long, from the seafloor through the décollement, were set at Sites 948 and 949. Perforated casing within the décollement zone allowed hydrologic experiments within the main fault.

3. Packer experiments were run successfully to measure fluid pressure and permeability in the décollement zone from within the cased holes.

4. Vertical seismic profiles (VSPs) were collected inside the cased holes to calibrate the seismic reflection models. An offset VSP at Site 949 used 18 bottom-shot explosions to determine shear-wave polarization to study crack alignment and hence stress orientation and structural fabrics. 
Leg 156

Preliminary Report

Page 20

5. Holes at Sites 948 and 949 were instrumented with temperature and pressure sensors, and at Site 949 a continuous fluid sampler, that are designed to collect data over long periods, to assess the episodicity of fluid behavior.

Cores from the fault zone include lower to middle Miocene claystone, underlain by lower Miocene and upper Oligocene variegated claystones, with muddy turbidites and redeposited chalk. The fault is a 31-m-thick zone of scaly fabric, fracture networks, and stratal disruptions interleaved with intact intervals of sediment. Variations in interstitial-water chemistry exhibit both diffusive and advective characteristics. Geochemistry-depth profiles characterized by low-Cl fluid intervals are consistent with active focused fluid flow along conduits from greater depth.

The anomalously high porosities in the vicinity of the décollement zone from the Site 947 and Site 948 LWD data suggest high fluid pressures. It seems likely that the high porosities are maintained by fluid influx, as dilatant (hydrofractured) zones.The more localized occurrence in the two narrow zones at Site 948 suggests that high-pressured zones may occur throughout the décollement, and that they are not apparent everywhere from seismic data owing to limitations in seismic resolution.

High pore pressures and related formation instability caused operational difficulty at all Leg 156 sites. At Site 947 the drill string became stuck in the 15-m-thick high-porosity section just above the décollement. Constant infilling of the casing by sediment and outflow of sediment-laden water from the reentry cone at Site 948 continued until flow was stopped with a heavy mixed barite and bentonite mud. Sediment also rapidly filled the casing at Site 949 prior to installation of a mechanical plug at the bottom to stop the flow.

Initial analysis of packer results from Site 948 suggests that pressure may have increased to $90 \%$ of lithostatic during the period in which the screened section was isolated, providing tantalizing indications of high in situ fluid pressure. Confirmation, however, can only follow shore-based work. 
Leg 156

Preliminary Report

Page 21

\section{REFERENCES}

Hubbert, M.K., and Rubey, W.W., 1959. Role of fluid pressure in mechanics of overthrust faulting: \#1 - Mechanics of fluid-filled porous solids and its application to overthrust faulting. Geol. Soc. Am. Bull., 70:115-166.

Kastner, M., Enderfield, H., and Martin, J.B., 1991. Fluids in convergent margins: what do we know about their composition, origin, role in diagenesis and importance for oceanic chemical fluxes. Philos. Trans. R. Soc. London (A), 335:275-288.

Knipe, R.J., Agar, S.M., and Prior, D.J., 1991. The microstructural evolution of fluid flow paths in semi-lithified sediments from subduction complexes. Philos. Trans. R. Soc. London (A), 335:261-273.

Langseth, M.G., and Moore, J.C., 1990. Introduction to special section on the role of fluids in sediment accretion, deformation, diagenesis, and metamorphism in subduction zones. J. Geophys. Res., 95:8737-8742.

Moore, J.C., Biju-Duval, B., et al., 1982. Offscraping and underthrusting of sediment at the deformation front of the Barbados Ridge: Deep Sea Drilling Project Leg 78A. Geol. Soc. Am. Bull., 93:1065-1077.

Moore, J.C., and Vrolijk, P., 1992. Fluids in accretionary prisms. Rev. Geophys., 30:113-135.

Screaton, E.J., Wuthrich, D.R., and Dreiss, S., 1990. Permeabilities, fluid pressures, and flow rates in the Barbados Ridge complex. J. Geophys. Res., 95:8997-9007.

Shi, Y., and Wang, C.Y., 1988. Generation of high pore pressures in accretionary prisms: inferences from the Barbados subduction complex. J. Geophys. Res., 93:8893-8910.

Shipley, T.H., Moore, G.F., Bangs, N.L., Moore, J.C., and Stoffa, P.L., 1994. Seismically inferred dilatancy distribution, northern Barbados Ridge décollement: implications for fluid migration and fault strength. Geology, 22:411-414. 
Leg 156

Preliminary Report

Page 22

\section{FIGURE CAPTIONS}

Figure 1. Index chart of the Lesser Antilles. Stippled zone is the extent of the northern Barbados Ridge accretionary prism. The Tiburon Rise dams along-axis trench transport, partly explaining the reduction in width of the prism to the north. A box illustrates the location of the DSDP/ODP transects. The box is approximately the size of the 3-D seismic survey that identified the drilling locations on Leg 156 (figure modified from N. Bangs, personal communication). Bathymetry shown in meters.

Figure 2. Map of décollement showing the Leg 156 drill sites superposed on a seismic amplitude map. The amplitude map is based on digitized 3-D seismic data. The frontal thrust, DSDP, and other ODP drill sites are shown.

Figure 3. Seismic section illustrates reflection characteristics of the décollement at Sites 947 and 948. Section is in depth using velocity function derived from Site 671 (Shipley et al., 1994). Site 948 prism velocity $=1740 \mathrm{~m} / \mathrm{s}$; underthrust section velocity $=1779 \mathrm{~m} / \mathrm{s}$; Site 947 prism velocity $=$ $1777 \mathrm{~m} / \mathrm{s}$; underthrust section velocity $=1811 \mathrm{~m} / \mathrm{s}$. Section gain was equalized with a 500-ms symmetric moving window.

Figure 4. Seismic section illustrates reflection characteristics of the décollement at Site 949. Section is in depth using velocity function derived from Site 671 (Shipley et al., 1994). Specifically at Site 949 the prism velocity used was $1699 \mathrm{~m} / \mathrm{s}$, and the underthrust section velocity was $1743 \mathrm{~m} / \mathrm{s}$. Section gain was equalized with a 500-ms symmetric moving window. 
Leg 156

Preliminary Report

Page 23

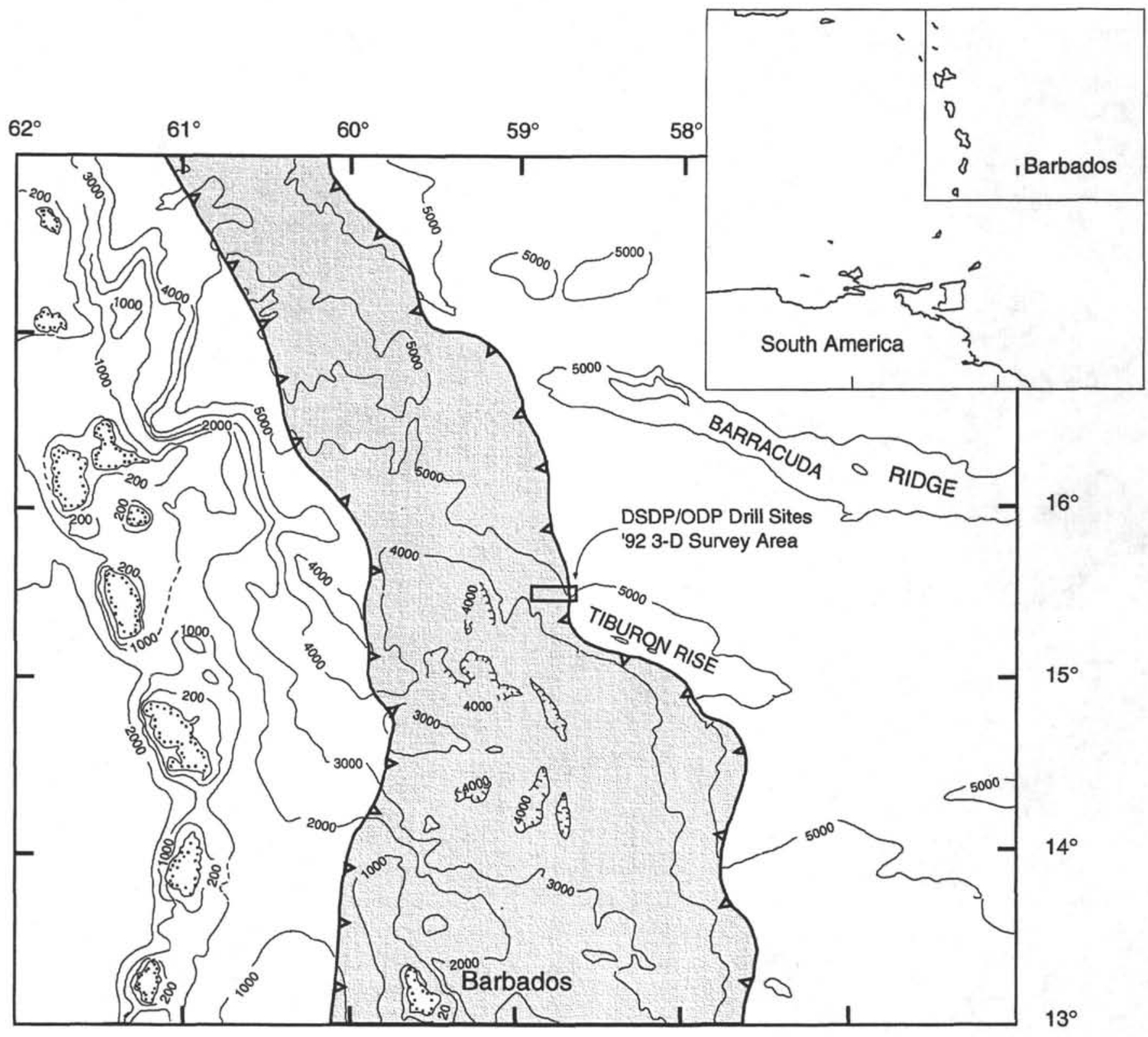

Figure 1 


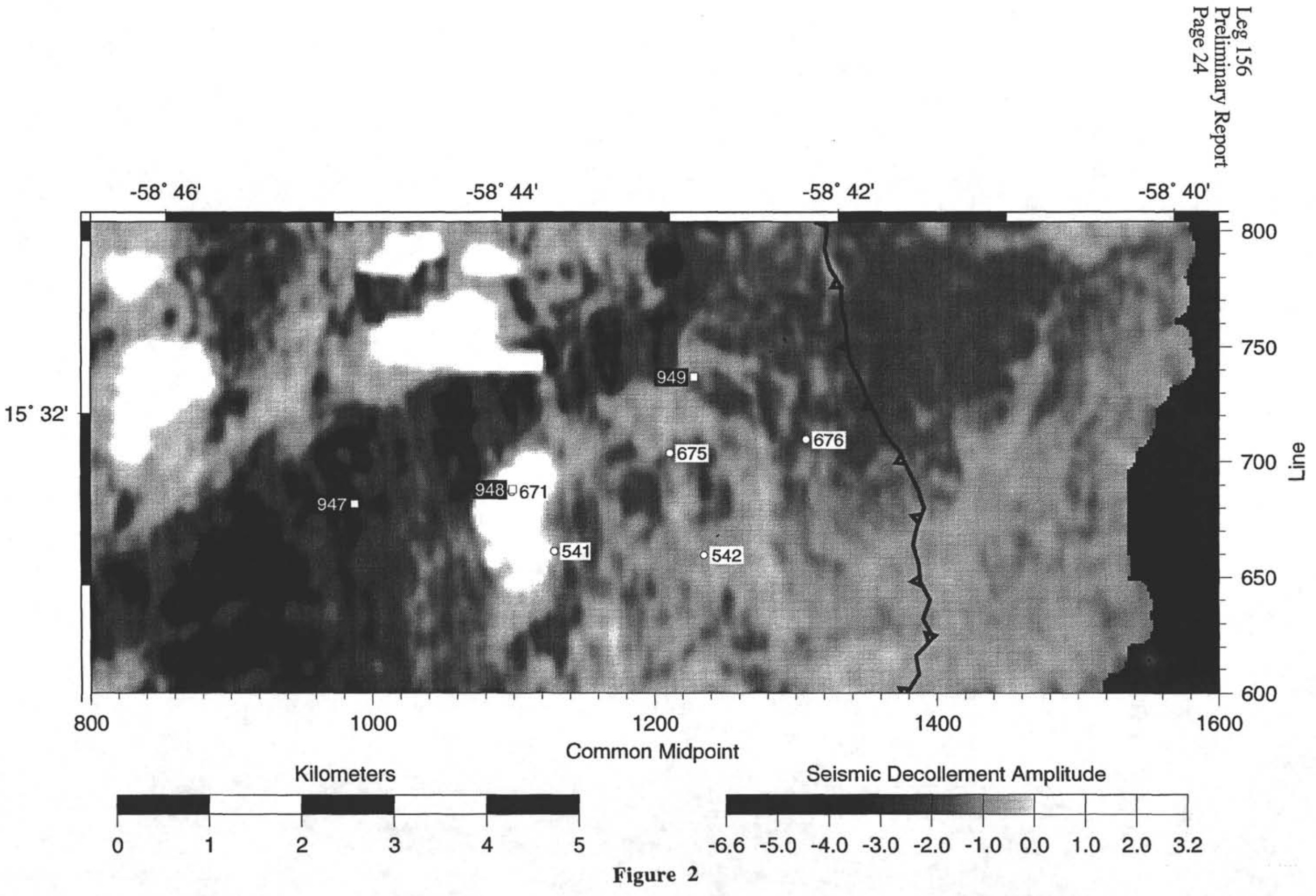


Leg 156

Preliminary Report

Page 25

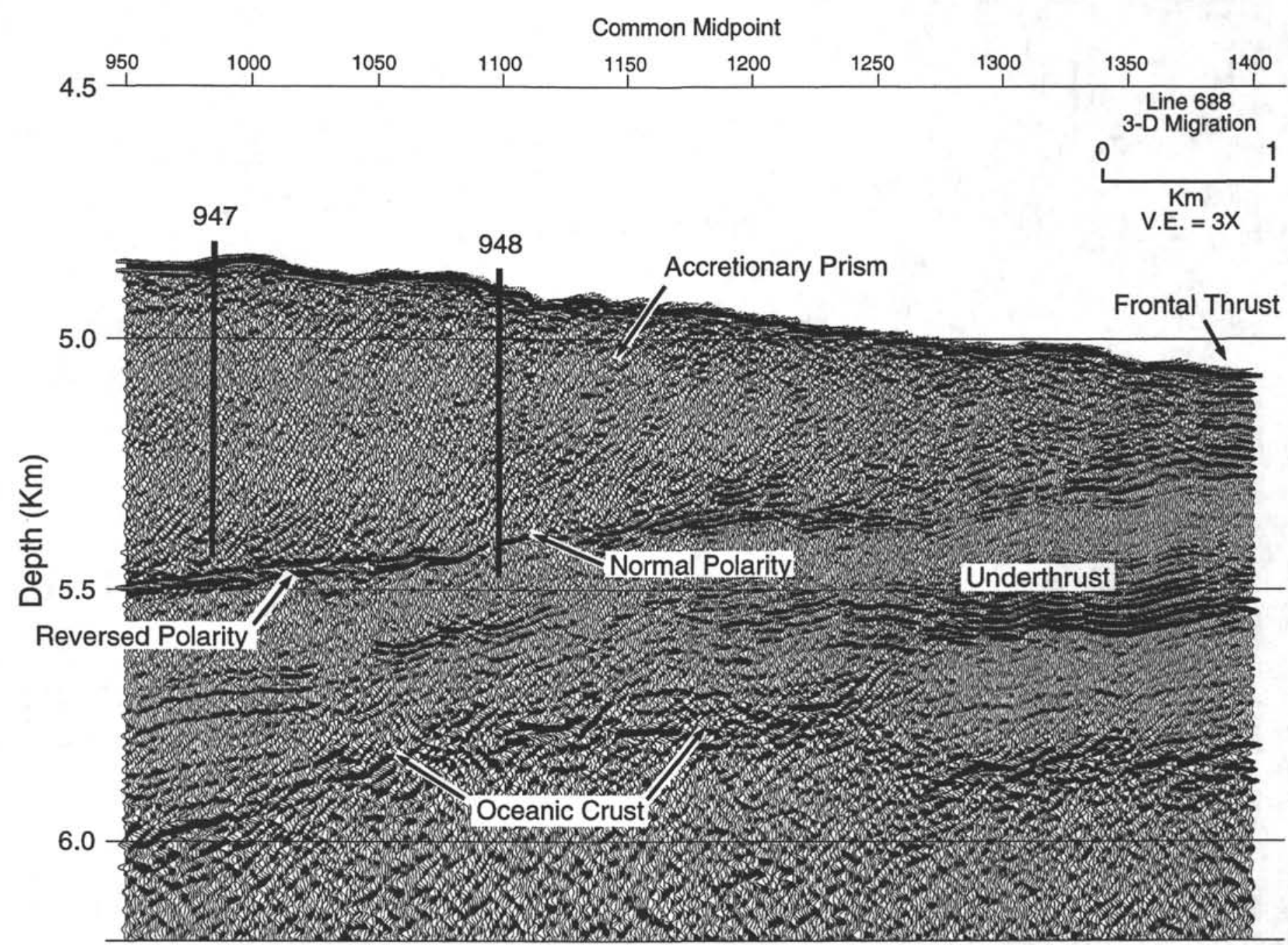

Figure 3 


\section{A}

Line 736

3-D Migration

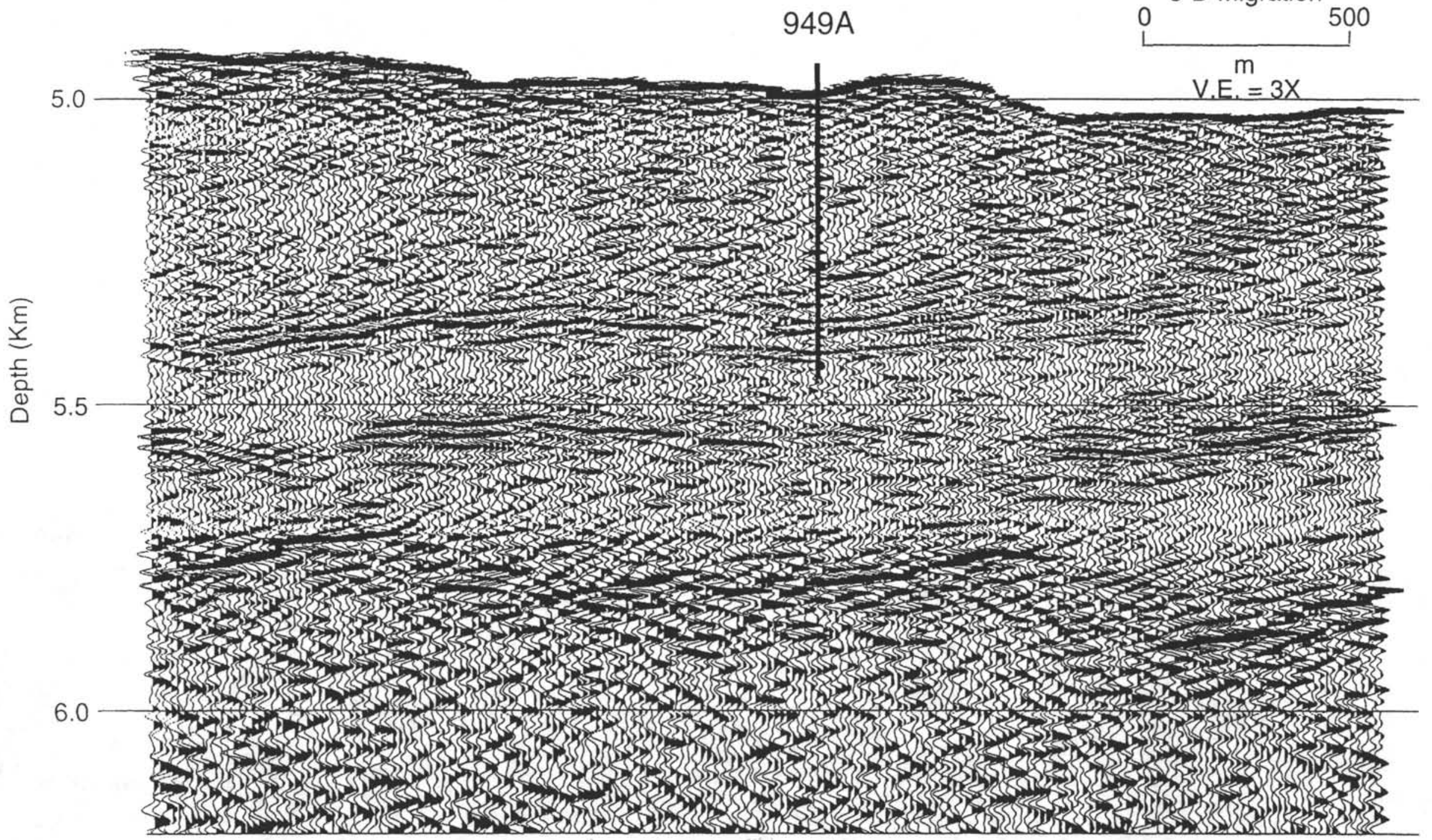
Figure 4 
OPERATIONS REPORT 
Leg 156

Preliminary Report

Page 28

The ODP Operations and Engineering personnel aboard JOIDES Resolution for Leg 156 were:

Operations Superintendent:

Development Engineer:

Schlumberger Wireline Logging Engineer:

Schlumberger LWD Engineer:

US/Canada CORK Technician:

French CORK Technician:

Offset VSP Shot-firer:
Glen Foss

Tom Pettigrew

Jim Hyde

Chris Wood

Bob Macdonald

François Harmégnies

Kevin Smith 
Leg 156

Preliminary Report

\section{Overview}

Page 29

ODP Leg 156 was an ambitious operational program of cased-hole installations and downhole measurements in a region known for its difficult operating conditions (Table 1). Previous drilling efforts on the northern Barbados Ridge had proven the area to be of great scientific interest, but drilling difficulties were encountered that frustrated attempts to investigate the nature of fluids and their flow through the accretionary prism and the underlying décollement. As at other convergent margins, the sediments of the accretionary prism and the thrust-fault zones are characterized by elevated pore pressures, and unstable hole conditions result when they are penetrated.

Conventional drilling and coring techniques as applied by DSDP and the ODP historically have produced disappointing results in such areas. Leg 156 was dedicated to adapting a higher level of drilling and logging technology used by the petroleum industry to the problems defined on earlier legs. In addition, advanced geophysical and geochemical measurement and sampling techniques were supplied by the scientific community.

During Leg 156 operations, eight holes were drilled at three sites, all in water depths of about $5 \mathrm{~km}$ (Table 2). Two of the holes were dedicated to logging-while-drilling (LWD) efforts, and two were cased reentry holes that were left fitted with instrumented borehole seals (CORKs) for long-term geophysical measurements. With the emphasis on downhole operations, the coring program was curtailed, and only three holes had significant cored intervals. A transect of three sealed reentry sites had been planned, but a sequence of operational problems consumed much of the operating time that had been allotted for the third site.

Significant operational achievements and highlights of Leg 156 included several DSDP/ODP precedents, such as:

First and second triple-casing-string reentry installations

First use of underreamers to open hole diameter below casing

First use of a downhole fluid motor to advance casing while drilling

First setting of a mechanical-set packer (bridge plug)

First use of the (stingerless) Sub-Sea Release cement plug system

First use of a mechanical seal to close a casing/casing annulus

First use of screened casing to isolate an unstable formation interval

First use of hydrostatic "kill" methods to achieve instrument emplacement 
Leg 156

Preliminary Report

Page 30

First LWD logging (two holes)

First successful wireline logging through a décollement

First cement-bond log for evaluation of casing cementing effectiveness

First use of the drillship as a deployment vehicle for explosive seismic sources

In addition to these achievements, two CORKs were installed (with sensor strings and data loggers), multiple VSPs and packer permeability experiments were carried out, 23 hole reentries were made, and the drill crew tripped about $135 \mathrm{~km}$ of pipe.

There were several setbacks during the cruise that were due both to the failure of mechanical components to function as intended and to human error. Those are to be expected on a "technical frontiers" cruise. The heroes of Leg 156 were the members of the drilling crew, the rig mechanics, and the welders, who persevered and overcame the obstacles.

\section{Barbados Port Call}

ODP Leg 156 began with the first mooring line to the dock at Bridgetown Harbor, Barbados, at 0615 EST (local time) on 24 May 1994. The port call entailed a heavy logistical workload with the loading of casing and other major supplies for the hardware-intensive Leg 156 drilling program. Special drilling hardware loaded for Leg 156 included 215 joints of 27.3-cm (10-3/4") and 34-cm (13-3/8") casing; mud motors; underreamers; a reentry cone assembly; three instrumented borehole seal (CORK) assemblies; three submersible vehicle landing platforms; logging-while-drilling (LWD) tools, and various drill collars, casing hangers, and casing-handling equipment. Other work items related to the Leg 156 scientific program included the installation and America Bureau of Shipping (ABS) inspection of an auxiliary explosives magazine and pressure-testing of the mud recirculation and shearing piping.

Permission to occupy the Leg 156 operating area was not received from French authorities until the intended sailing date. Departure was scheduled for 1900 EST on 27 May, pending the arrival of the LWD tools by air freight. Difficulties in loading and unloading the long, heavy tools on the aircraft resulted in delays of about $4 \mathrm{hr}$. After arrival and checkout of the tools, JOIDES Resolution departed Barbados at 2300 EST on 27 May. 
Leg 156

Preliminary Report

Page 31

\section{Bridgetown to Site 947}

Leg 156 operations were in a small area on the northern Barbados Ridge about $260 \mathrm{~km}(140 \mathrm{nmi})$ north-northeast of the northern tip of Barbados and $240 \mathrm{~km}(130 \mathrm{nmi})$ east-northeast of the island of Martinique. The transit of about $315 \mathrm{~km}(170 \mathrm{nmi})$ was made at an average speed of $21.7 \mathrm{~km} / \mathrm{hr}$ (11.7 kt). After the ship had navigated to a waypoint about $9 \mathrm{~km}$ ( $5 \mathrm{nmi}$.) east of the operating area, a turn to the west was made and speed was reduced for precision navigation across the three proposed drill sites. Positioning beacons were launched, in order, as the positions of sites NBR-1, 948 (NBR-2), and 947 (NBR-3) were crossed. That approach was taken to minimize site-location time and to expedite the drilling of a transect of holes dedicated to LWD logging. No seismic gear had been streamed, so the vessel was able to turn quickly and take station on the beacon at NBR-3 (947A), which was dropped at 1445 EST on 28 May.

\section{Depth Discrepancies at Sites 947 and 948}

Determining true seafloor depths relative to the drill floor proved to be challenging at both Site 947 and 948 owing to a variety of problems. The most serious problem was an early miscount in the pipe tally that led to an initial overestimate of pipe length. Identification of the inconsistency and determination of how best to rectify it were complicated because of actual differences in water depth from hole to hole at the site, variations in wireline and pipe stretch, installation of a new (and therefore partly "uncalibrated") coring line, and a later additional error in "stinger" (pipe) length. Pipe depths reported throughout this "Operations" section in meters below rig floor (mbrf) have been corrected for the error, with uncorrected depths shown for reference in parentheses. Depths in meters below seafloor (mbsf) have not been changed, because these were correct all along, being referenced to mud line via the mud-line core (for coring depths) or log response (for wireline and logging-while-drilling data). All other depths shown in other sections in this Preliminary Report are corrected.

\section{Site 947}

\section{Hole 947A: Logging-While-Drilling}

The first LWD was on the westernmost site of the transect, which was located on the thicker portion of the accretionary prism and was suspected to have high pore-fluid pressures at depth. 
Leg 156

Preliminary Report

Page 32

A bottom-hole assembly (BHA), composed of the LWD tool string, all new drill collars, and a new drilling jar, was assembled to begin the pipe trip. Relatively slow progress was made because of the standard practices of measuring and passing a drift through the drill string on the initial pipe trip of an ODP leg. A float valve was installed above the bit, so it was necessary to stop the trip on several occasions to fill the pipe.

Shortly after the pipe trip began, the acoustic release of the positioning beacon was activated by the pulses of the precision depth recorder (PDR) while a check of water depth was being made. A backup beacon was launched immediately to prevent loss of position. The original beacon eventually was recovered by careful maneuvering of the ship without interruption of the trip. Recovery operations and subsequent positioning were complicated by the presence of a strong southwest-to-northeast surface current--the explanation for the exceptional transit speed.

After the top drive was deployed, the Anadril depth-tracking system was calibrated against block travel, and circulating pressure was recorded for varying pump rates. The bit then was lowered without rotation or circulation to "feel for bottom." Contact with the seafloor was registered by the rig weight indicator at $4881 \mathrm{~m}$ from the driller's datum (dual elevator stool--DES). The drill-pipe measurement was $7 \mathrm{~m}$ deeper than the PDR reading of $4884 \mathrm{~m}$.

Drilling then proceeded with only some minor problems associated with depth control on a floating platform. In the very soft upper sediments, the rate of penetration (ROP) was faster than optimum for data density, but the high rate was necessary to keep the bit in contact with the bottom of the hole and maintain depth control. Below about 70 mbsf, the sediment firmed, and the desired ROP of $60 \mathrm{~m} / \mathrm{hr}$ was maintained fairly well to total depth.

Though no hole-cleaning problems were experienced, the hole was swept with sepiolite "pills" each $100 \mathrm{~m}$ beginning at $300 \mathrm{mbsf}$. Elevated circulating pressure and torque after a connection at 555 mbsf were the first signs of hole problems. A sepiolite pill was circulated while the ensuing two joints were drilled to $574 \mathrm{mbsf}$, but it was ineffective in reducing either pressure or torque. An additional connection was made, but the pipe became stuck in the process. After a few minutes of working the pipe, it was freed by a single blow of the drilling jar. Torque returned to near normal, but continued high circulating pressure indicated that the annulus had packed off and that circulation was into the formation. That indication was supported when additional mud sweeps 
Leg 156

Preliminary Report

Page 33

failed to alleviate the situation. An attempt was made to drill down the last joint of pipe in the string, but penetration was halted at $583.7 \mathrm{mbsf}$ by hydraulic resistance and high torque. A short trip then was made up into stable hole at $525 \mathrm{mbsf}$ and then back to about $540 \mathrm{mbsf}$, where increased circulating pressure again was noted. Attempts to ream the apparently constricted hole and regain normal drilling parameters were unsuccessful despite mud sweeps and repeated passes of the bit through the interval.

A repeat section of LWD log then was made by back-reaming the hole section from 554 to 496 mbsf at a rate of $60 \mathrm{~m} / \mathrm{hr}$ before the top drive was racked and the pipe was tripped. Because the unstable zone was identified as a thrust fault well above the décollement, it was not considered necessary to plug the hole. When the LWD tools reached the surface, the radioactive source was removed and the log data downloaded to a laptop computer. The drill bit cleared the rig floor at 1600 EST on 30 May.

\section{Site 948}

\section{Hole 948A: Logging-While-Drilling}

Following completion of logging-while-drilling (LWD) operations in Hole 947A, the bottomhole assembly (BHA) and LWD tools were returned to the surface to check data quality and battery power. The LWD tools were re-initialized, and the source was reloaded. The same drilling assembly was run back to the seafloor while the Site 947 beacon was switched to standby mode and the vessel was offset $1800 \mathrm{~m}$ in DP mode to Hole 948A (NBR-2), sited close to Site 671 (Leg 110).

An attempt was made to determine water depth by tagging the seafloor. A tenuous call was made when the motion compensator appeared to close slightly with the bit at 4955 (4945) mbrf. The LWD depth of 4940 (4950) mbrf, based on tool response, was adopted as the official seafloor depth of Hole 948A.

Difficulty was experienced in controlling the rate of penetration (ROP) during LWD operations in the uppermost $100 \mathrm{~m}$ of the section, but experience gained in Hole 947A helped the drillers to maintain a slower and more uniform ROP for better log quality for the rest of the hole. Again, hole conditions were good, and widely spaced sepiolite pills were used only to flush possible large cuttings/cavings from the annulus. 
Leg 156

Preliminary Report

Page 34

As in Hole 947A, increased circulating pressure was the precursor of drilling problems, beginning near 515 mbsf and increasing as drilling continued. Mud sweeps did not help. Torque remained normal until the pump was shut down for a connection at 584 mbsf; then it was difficult to regain rotation. A wiper trip was begun and the pipe stuck briefly at 525 mbsf. The system held 3.4 MPa (500 psi) standpipe pressure with the pump off until the bit had been raised above about 470 mbsf, indicating a packed-off condition. Tight hole was encountered on the down-trip at about $502 \mathrm{mbsf}$ (identified from logs and Hole 671B cores as the top of the décollement). Attempts to ream back to total depth were unsuccessful in advancing the bit beyond 535 mbsf because of high torque and sticking.

The interval from 535 to 448 mbsf was back-reamed for a repeat log section before the bit was run back to 467 mbsf. Because the décollement had been penetrated, the hole was back-filled with $1.4 \mathrm{~kg} / \mathrm{L}$ (12 lb/gal) bentonite/barite mud in an attempt to isolate it hydrologically from holes to be drilled nearby.

When the drill string had been tripped and the LWD tools stripped of data and laid down, the positioning beacon was switched to standby mode. JOIDES Resolution departed Hole 948A at 1630 EST on 1 June.

\section{Barbados Port Stop}

A brief port call was scheduled primarily to offload the LWD tools, which had been leased at a day-rate, but it also allowed onloading of freight that had arrived too late to make the primary port call. Prior to departure for Barbados, the ship detoured $7 \mathrm{~km}$ east to stop briefly over proposed site NBR-1 and acoustically switch that beacon to standby mode. The first mooring line was put over in Bridgetown Harbor at 0915 EST on 2 June.

After the LWD tool shipment was off-loaded, several pieces of freight were on-loaded, including explosives for the planned shear-wave VSP experiment. Five personnel

disembarked, and three additional personnel embarked. The 4.5-hr port call ended with the final line aboard at 1445 EST. 
Leg 156

Preliminary Report

Page 35

Strong trade winds from forward of the beam held the outward average speed to about $10.5 \mathrm{kt}$. The vessel proceeded to a waypoint $4.6 \mathrm{~km}$ west of Site 948 , turned, and made its final approach into the wind. At 0500 EST on 3 June, acoustic commands restarted the positioning beacon, and the vessel shifted to DP mode at 0530 EST, once thrusters and hydrophones were lowered.

\section{Site 948 (continued)}

\section{Hole 948B: Jetting Testing and Mud-line Coring}

An abbreviated, lightweight BHA was assembled with a $29.1 \mathrm{~cm}\left(11-7 / 16^{\prime \prime}\right)$ roller-cone bit, as success during Leg 110 in coring through the décollement had been attributed in part to larger bit size and greater annular clearance. The drill string was run at the positioning coordinates of the planned reentry hole to determine seafloor depth and the thickness of soft sediments.

When the top drive was deployed, the bit was lowered until resistance was noted on the weight indicator at 4950 (4960) mbrf. Pump circulation was started, and a jetting test was performed to determine the depth to which $40.6 \mathrm{~cm}$ (16") conductor casing could be advanced without rotation. Satisfactory jetting was achieved to 4998 (5008) mbrf, 48 mbsf.

The bit was pulled clear of the seafloor for a "mud-line" advanced piston core (APC). To avoid the area of greatest disturbance, a minimal (4.5-m) offset was entered into the automatic station-keeping system. The APC was lowered on the coring line and "fired" with the bit at 4943.5 (4953.5) mbrf. The 9.5-m core barrel recovered $3.71 \mathrm{~m}$ of sediment, and seafloor depth was fixed at 4949 (4959) mbrf. One joint of drill pipe then was laid out, and the vessel was moved to the positioning coordinates of Hole 948A.

\section{Hole 948C: Coring and Logging}

To locate Hole 948C as closely as possible to LWD-logged Hole 948A (and Leg 110 Hole 671B), the same beacon and positioning offset coordinates were used. The APC was deployed during the offset, and an attempt was made to core the sediment/water interface, with the corer actuated from 4933 (4943) mbrf. The APC barrel failed to reach the seafloor and recovered 
Leg 156

Preliminary Report

Page 36

only a "water core." The bit was then lowered $9.5 \mathrm{~m}$, the full length of the APC stroke, and the process was repeated. On the second attempt, the core chamber was completely filled with $10.1 \mathrm{~m}$ of sediment. On the assumption that the APC had been fired from the seafloor, water depth was set at 4942.5 (4952.5) mbrf.

A "blind" inner core barrel of the extended core barrel (XCB) configuration was pumped to the bit, and the upper sediment section was drilled without coring to $421 \mathrm{mbsf}$. With the bit at 64 and 102 mbsf, the core barrel was retrieved, and temperature measurements were made with the water-sampling temperature probe (WSTP) deployed in temperature-only mode with an XCB barrel. WSTP depths reported are greater than bit depths, because the probe tip extends $1.1 \mathrm{~m}$ beyond the bit.

When the WSTP from 102 mbsf was being recovered at about $2900 \mathrm{~m}$ below the rig floor, the coring line parted high in the derrick. The lower end of the break became fouled in the line wiper assembly on the traveling block, so the instrument did not fall back down the drill string. The upper end of the break traveled over the crown sheaves and fell to the coring-winch platform. A delay of about $3 \mathrm{hr}$ occurred while the line was clamped off, restrung, and reattached to the coring-winch drum. The WSTP was then recovered without incident.

Drilling then continued, with additional WSTP runs at 199, 247, 326, and 421 mbsf. All the temperature measurements produced good data. There were no hole problems in the drilled interval, but the ROP was considerably lower than in the LWD holes. Continuous XCB coring began at 421 mbsf. Core recovery was very good from the beginning, but the cores exhibited moderate-to-severe "biscuiting." No indications of hole problems were encountered as the décollement zone was penetrated around 500 mbsf, except that a circulating pressure increase of about 200 psi was noted beginning around 507 mbsf. Mud sweeps each second core were initiated at that time but had no effect on the pressure. "Knobby" drilling joints were used, beginning at $517 \mathrm{mbsf}$, in anticipation of drill-string sticking. At $534 \mathrm{mbsf}$, the drill string began torquing severely during a core-retrieval wireline trip.

A short trip then was made in an attempt to stabilize the hole and ream the constricted interval. The string stuck rotationally and vertically each time the pump was stopped and overpulls of up to $41,000 \mathrm{~kg}(90,000 \mathrm{lb})$ were required to free the string. As in the earlier holes, there was 
indication that the annulus was packed off and that circulation was into the formation. Standpipe pressure remained at 2.6-3.4 MPa (400-500 psi) with the pump stopped. Pressure and torque indications returned to normal after the bit had been pulled above $507 \mathrm{mbsf}$. When the hole had been reamed back to total depth and swept with mud, torque and pressure were close to normal, and coring resumed.

Drilling parameters continued to improve with depth, apparently because the formation below the décollement zone was stable and possibly because the 21.0-cm (8-1/4") drill collars had passed through the constricted zone. With Core 156-948C-19X to $592 \mathrm{mbsf}$, the depth target of the hole had been reached, and coring was terminated. Core recovery for the XCB-cored interval was about $94 \%$, vs. about $79 \%$ for the equivalent interval in Hole 671B.

After a mud sweep, a wiper trip was made to prepare the hole for wireline logging. Overpulls of $27,000-32,000 \mathrm{~kg}(60,000-70,000 \mathrm{lb})$ were required to pull the bit through the décollement zone. Only light drag was experienced above 517 mbsf, but the pipe was "wet" (full of water) for over $100 \mathrm{~m}$ above that point. The upper part of the hole, to $103 \mathrm{mbsf}$, was in good condition. On the down-trip, the top drive was picked up when resistance was met at about 430 mbsf. The bit was washed ahead without rotation to test the feasibility of side-entry sub (SES) logging operations, with a second pass with rotation to ream the hole before each connection. Tight hole persisted from 430 to about $535 \mathrm{mbsf}$, with 7,000-9,000 kg $(15,000-20,000 \mathrm{lb})$ weight required to wash through the interval from 511 to $516 \mathrm{mbsf}$. The lowermost section of hole from 535 to 592 mbsf was open, and no fill was noted at total depth. A sweep of $6,500 \mathrm{~L} \mathrm{(40} \mathrm{bbl)} \mathrm{of} \mathrm{sepiolite} \mathrm{mud} \mathrm{was} \mathrm{circulated} \mathrm{through} \mathrm{the} \mathrm{hole,} \mathrm{and} \mathrm{the}$ bit was pulled to logging depth at 64 mbsf. Drag of about $14,000-18,000 \mathrm{~kg}(30,000-40,000$ lb) was noted as the "trouble zone" was passed.

The SES then was made up into the drill string, and the logging sheaves were rigged. A combination sonic-density-gamma ray logging tool string was assembled and run down the pipe. An attempt was made to log the open hole conventionally without lowering the drill string, but bridging in the hole just below the bit foiled the first attempt. Two stands of drill pipe were added, but with the same result. The drill string then was run in to $477 \mathrm{mbsf}$, where resistance was met. After the top drive was deployed, pump circulation was successful in washing through the décollement zone with a maximum of $14,000 \mathrm{~kg}(30,000 \mathrm{lb})$ weight 
Leg 156

Preliminary Report

Page 38

applied. Below $535 \mathrm{mbsf}$, there was no more resistance, and the bit was advanced to 563 mbsf. The logging tool was lowered out of the pipe at that depth and came to rest on an obstruction at 568 mbsf. No further time was spent on attempting to reach total depth, and the pipe was withdrawn while the log was recorded up-hole. Open hole was logged to the end of the drill string at $80 \mathrm{mbsf}$, and the gamma-ray curve continued inside the pipe to record the sediment/water interface. Restrictions in the hole caused high overpull on the logging tool, even though the bit had passed just ahead of it. The caliper log curve confirmed that most of the hole was either badly over- or under-gauge and that hole conditions were too poor to warrant additional logs.

When the logging tools and SES had been rigged down, the drill string was run to hydrostatically plug the hole from just below the fault zone to near the seafloor. The top drive was picked up at $459 \mathrm{mbsf}$, the first resistance in the hole, and the hole was reamed to 498 mbsf. Since the logging run, the hole had become much tighter, and drilling parameters were as though new hole was being made. Reaming was stopped, and the hole was displaced with $74,100 \mathrm{~L}(455 \mathrm{bbl})$ of $1.6 \mathrm{~kg} / \mathrm{L}$ (14 lb/gal) of barite/bentonite mud. Fresh-water-based mud was used in the hope that it would increase the swelling of hydrophilic clays and hasten closure of the hole. The drill string then was recovered, with all components on deck at 0300 EST on 9 June.

\section{Hole 948D: Drilling, Casing, and Downhole Experiments}

A new coring line was installed while the ship was offset to the coordinates of Hole 948B, where the reentry/borehole observatory installation was to be located. A 43-m string of 40.6cm (16") casing was assembled below a preassembled reentry cone, comprising three joints of range-three 40.6-cm (16") casing, an adapter sub for a 34.0-cm (13-3/8") casing hanger, and the 40.6-cm (16") casing hanger. A 37.5-cm (14-3/4") drill bit and a 44.5-cm (17-1/2") underreamer assembly were made up to a BHA of drill collars, with the casing-running tool inserted at a point in the BHA that placed the bit opposite the casing shoe. The BHA was lowered until the casing hanger in the lower section of the reentry cone could be engaged by the running tool. When the entire casing/cone/BHA assembly was a unit, the moonpool doors were opened and the pipe trip begun. 
Just above the seafloor, the top drive was deployed, and jetting of the casing began at 1145 EST on 10 June. Jetting-in was slowed, because some of the water that normally would flow through the bit jets was diverted through the underreamer. Penetration came to a halt when the skirt of the reentry cone was calculated to be about $1.5 \mathrm{~m}$ above the seafloor. That was within the normal range of error in determining seafloor depth, and circulation was stopped with the casing shoe at 4990.5 (5000.5) mbrf. The drill string was lowered to transfer the weight of the casing/cone to the seafloor and turned to the right to release the assembly. The number of turns and torque indications signaled a "textbook" release, and the string was advanced about $1.5 \mathrm{~m}$ with little resistance.

Circulation was started at $45.2 \mathrm{~L} / \mathrm{s}(700 \mathrm{gpm})$ to open the underreamer arms. The $37.5-\mathrm{cm}$ (14-3/4") hole below the casing shoe was left for later opening to provide support for the 40.6$\mathrm{cm}(16 ")$ casing while the sediment reconstituted. Drilling and underreaming then continued at a rapid rate to the planned depth of 5428 (5438) mbrf ( $479 \mathrm{mbsf}$ ) for the casing rathole.

As the string was pulled back with the underreamer arms closed, minor drag was noted about $10 \mathrm{~m}$ off total depth. The lowermost $24 \mathrm{~m}$ of the hole was re-reamed before the top drive was set back for the trip out. Just below the 40.6-cm (16") casing shoe, the top drive was redeployed, and the interval of 37.5-cm (14-3/4") hole just below the casing was reamed to $44.5 \mathrm{~cm}(17-1 / 2 ")$. When the BHA passed through the reentry cone, the running tool reengaged its bushing, which was held in place at the casing hanger with shearpins. An upward pull of about $9,000 \mathrm{~kg}(20,000 \mathrm{lb})$ was required to shear the pins and free the drill string for retrieval. The drill string then was pulled, and the BHA was dismantled, with all components on deck at 2000 EST on 11 June.

Thirty-seven joints of 34.0-cm (13-3/8") casing were run and attached to the drill string. The drill pipe was tripped to reentry depth, with five stops to fill the string with water (because the casing float shoe had no automatic-fill device). During the fourth stop, the vibration-isolated TV (VIT) frame was deployed and latched around the drill pipe for simultaneous lowering with the drill string. Reentry was made at 1745 EST on 12 June.

No significant resistance was met as the casing was lowered into the hole until it reached 219 mbsf, where drag began. At 239 mbsf, all the casing weight below the seafloor was 
Leg 156

Preliminary Report

Page 40

insufficient to advance the casing farther. The top drive was deployed at that point so that the casing could be "washed" to the bottom of the hole. Circulation seemed to help little, and slow progress was made by alternately raising the casing and applying all available weight while pumping at rates of up to $32.3 \mathrm{~L} / \mathrm{s}$ (500 gpm). The tight interval corresponded roughly to an interval of high overpull and reduced hole diameter on the density log. Good progress was made with the casing at 276-326 mbsf. Firm resistance again was encountered at $326 \mathrm{mbsf}$, and no amount of "working" and circulation could advance the casing shoe past $336 \mathrm{mbsf}$. After $1.5 \mathrm{hr}$ with no progress, the effort was abandoned, and the pipe trip was begun to recover the casing string to the ship.

The running tool arrived back at the rig floor at 1000 on 13 June, and preparations were made for recovering the casing and storing it in the riser hold. The casing hanger and uppermost casing joint were laid out as a unit. When the casing was raised farther, the second joint was noted to be visibly deformed near the bottom, and the third joint was completely collapsed. The upper end of the fourth joint also was deformed by the collapse. The collapse occurred because the drill string had not been filled with water frequently enough during the pipe trip and the hydrostatic pressure differential exceeded the collapse pressure of the casing. To determine the extent of damage, the VIT was deployed and run to the end of the casing string. The float shoe was sighted at the proper depth, confirming that no casing had been left in the hole, but lighting, viewing angle, and video quality combined to make any damage assessment inconclusive.

The damaged second, third, and fourth joints of casing were removed from the string. With full-open casing again accessible, a 31.1-cm (12-1/4") drill bit was lowered to the guide shoe to confirm that the remainder of the string was free of restrictions. Three new casing joints of equivalent length then were added to replace the failed joints, and the uppermost joint, with casing hanger, was reinstalled.

Because the hole was known to be obstructed to some degree and because the elapsed time since drilling already had exceeded 2 days, there was considerable concern about the chances of successfully emplacing the casing string without some additional hole conditioning. Thus, plans were made to reenter the hole with the bit/underreamer assembly used for the original drilling. For that operation to be conducted, the casing string had to be disassembled or stored 
off-centerline below the rig. It would have been relatively straightforward to hang off the string on the moonpool doors just forward of centerline, but two reentries were required, and it would be necessary to open the moonpool doors to deploy and recover the VIT. Rig personnel devised the alternative solution of suspending the casing from a pair of heavy padeyes on the rig floor support beams about $2 \mathrm{~m}$ forward of centerline. The load was transferred and suspended by means of two sets of heavy slings and shackles attached to a "spider clamp," which, in turn, supported the casing elevators (which were latched under the uppermost casing collar).

The $37.5 \mathrm{~cm}$ (14-3/4") bit and 44.5-cm (17-1/2") underreamer then were made up to a drilling BHA. After a routine trip and reentry, the bit was run to $183 \mathrm{mbsf}$ before the top drive was deployed. No resistance was "felt" until the bit reached 389 mbsf. Only minor torque and weight indications were noted as the hole was reamed to total depth. Two meters of new "rathole" then was made to 5430 (5440) mbrf (481 mbsf), and the hole was flushed with sepiolite mud. At 0030 on 15 June, the BHA had been recovered, and the bit and underreamer were on deck.

Slings again were used to transfer the weight of the casing string to the hoisting system and to return it to the rig floor, where it was made up to the DrilQuip casing-running tool. Reentry was made after the pipe trip to the seafloor, and the casing was lowered into open hole. Resistance was first encountered at $383 \mathrm{mbsf}$, and the top drive was picked up to provide circulating capability. Slow progress was made over the next $148 \mathrm{~m}$, with circulating rates of $12.9-22.6 \mathrm{~L} / \mathrm{s}(200-350 \mathrm{gpm})$ and up to $23,000 \mathrm{~kg}(50,000 \mathrm{lb})$ of casing weight required for much of the interval. During the wash-in operation, it was noted that all circulation returns to the seafloor were outside the 40.6-cm (16") casing string, causing the sediment to boil around the reentry cone. At the final drill-string connection ( $471 \mathrm{mbsf}$ ) before the casing hanger landed, the cementing swivel and safety valve (containing the plug-release dart) were attached to the final drilling joint and incorporated into the string below the top drive. The casing then was washed down the final $5 \mathrm{~m}$ until progress stopped and the 34.0-cm (13-3/8") casing hanger latched into the 16 " casing string. Latch-in was checked by taking a 14,000-kg (30,000-lb) overpull on the drill string. 
Leg 156

Preliminary Report

Page 42

With the casing in place, cementing operations began. Cement slurry was mixed to $1.8 \mathrm{~kg} / \mathrm{L}$ (15 lb/gal) with seawater and pumped through the cement swivel. When $32,900 \mathrm{~L}$ (202 bbl) had been mixed, the release dart was launched, and an additional 1,100 L ( $7 \mathrm{bbl})$ was pumped to fill the lowermost joint of casing. The cement slurry was followed by 3,300 L ( $20 \mathrm{bbl})$ of fresh water to flush the lines and was displaced with seawater. The dart landed in the top plug and required $13.8 \mathrm{MPa}$ (2000 psi) to shear pins and release the top plug, which subsequently "bumped" at the casing shoe when the cement had been displaced fully. During the displacement, circulating pressure increased steadily, indicating the buildup of hydrostatic pressure in the annular cement column, only to drop by about $1.4 \mathrm{MPa}$ (200 psi) approximately $1,900 \mathrm{~L}$ (500 gal) short of full displacement. The pressure indication was interpreted to mean that the formation had broken down and that the slurry had fallen some distance back down the annulus. A further disappointment was a strong backflow of water when the cementing hose connection was broken, indicating that the float valve in the casing shoe had not held and that the slurry was "U-tubing" farther down the annulus and into the casing.

As soon as the cementing hose had been disconnected, the weight of the casing string was set down on the cone, and the drill string was turned to the right to actuate the DrilQuip running tool. The operation was viewed with underwater television, and the string was observed to turn the required four revolutions--but only after abnormally high torque had been applied. When the drill string was raised to separate the running tool from the hanger, separation was not achieved, and the casing string remained attached.

Failure of the running tool to release left the rig with few options. Circulation was not possible because the casing was sealed by the plug at the bottom and the running tool at the top. It was possible only to apply torque and to put varying amounts of upward tension on the tool. Five hours was spent in "working" the pipe with torque and tension, with up to 2,500 N-m (18,000 $\mathrm{ft}-\mathrm{lb}$ ) torque applied. Also, circulating pressure was applied to break a possible hydraulic lock imposed by slurry in the annulus. That was effective in returning the cement top plug to the shoe after about $2,900 \mathrm{~L}$ ( $750 \mathrm{gal}$ ) had been pumped. Tension was kept below $27,000 \mathrm{~kg}$ $(60,000 \mathrm{lb})$ above casing weight for most of the time to avoid shearing the retaining lugs and unseating the 34.0-cm (13-3/8") casing string. The ship was offset $40 \mathrm{~m}$ in each quadrant in case positioning error was imparting lateral stress to the tool. When it appeared that normal 
Leg 156

Preliminary Report

Page 43

release could not be effected, the cementing equipment was removed from the string in preparation for heavy overpull. Overpull was applied in increments with the aim of shearing out and recovering the surface casing string before the cement could set. Between pulls, weight was slacked to the "neutral" point, and torque was applied. After a pull to $90,900 \mathrm{~kg}(200,000$ lb) over casing weight had been applied and released, the tool released under high torque, and the drill string spun free.

A round trip then was made for a drilling BHA equipped with a 31.1-cm (12-1/4") drill bit and a mechanical bit release (MBR). After another routine reentry, the bit was run into the hole. The trip proceeded with caution, because the casing was expected to be about half full of cement. Remarkably, no cement was tagged down to $18 \mathrm{~m}$ above the shoe. (Apparently the float valve had held after the top plug was pumped into place the second time.) The cement in the casing, the rubber/aluminum plugs, and the casing shoe were drilled out in $2 \mathrm{hr}$. The 5.5-m rathole then was cleaned/drilled out to $12-1 / 4$ " to the previous total depth, and a sweep of extra-high-viscosity bentonite mud was circulated to clean debris from the hole.

After the VIT had been deployed, the bit was pulled back to the seafloor. The string was pulled clear of the reentry cone, and the rig was offset clear of the cone while the rotary shifting tool (RST) was run down the pipe on the coring line. Release of the drill bit and bit disconnect onto the seafloor was recorded on videotape, and the VIT was held in position while the ship was offset back for reentry. Upon reentry, the open-ended BHA was lowered inside casing, the VIT was recovered, and the logging sheaves were rigged.

The first logging tool to be run was a Schlumberger Cement Attenuation (bond) Log (CBL) of the surface casing string. To avoid running the tool into open hole, the log was recorded up from about $14 \mathrm{~m}$ above the casing shoe to the end of the drill string at $51 \mathrm{mbsf}$. Log results showed good cement bonding ( $80 \%$ or better) about $52 \mathrm{~m}$ up from casing shoe (assuming inclusion of the lowermost $14 \mathrm{~m}$ ), partial cement bonding up an additional $118 \mathrm{~m}$, and free pipe for the upper $305 \mathrm{~m}$ of $34.0-\mathrm{cm}$ (13-3/8") casing. A vertical seismic profile (VSP) then was run, with 4,900- $\mathrm{cm}^{3}$ and 1,200- $\mathrm{cm}^{3}$ (300- and 120-in.3) air guns as the sound source and the Schlumberger Array Seismic Imager (ASI) tool as the downhole sensor. The VSP 
Leg 156

Preliminary Report

Page 44

covered the same interval as the CBL. As expected, excellent data were recorded in the well-cemented casing section. The signal quality was better than expected (though noisy) in the poorly cemented and uncemented casing above.

After recovery of the drill string, preparations were made for running 27.3-cm (10-3/4") production casing. About $13 \mathrm{hr}$ was required to assemble 39 joints of casing, with hanger and seal subs. Three joints of perforated casing covered with gravel-pack screen were run near the bottom of the string. At 0830 on 19 June, the entire casing string was hung off in the moonpool, and assembly of the inner (stinger) assembly began.

A 25.1-cm (9-7/8") drill bit was made up to the lower end of a 24.1-cm (9-1/2") Servco underreamer equipped with $38.1-\mathrm{cm}$ (15") arms, and the bit/underreamer assembly was attached to a 19.4-cm (7-5/8") Drilex positive-displacement mud motor (PDM). The hydraulics of the bit/underreamer/PDM assembly were tested in the moonpool by circulating with the mud pump through the top drive. Above the motor, a circulating sub, stabilizer, drill collars, and 12.7-cm (5") drill pipe completed the stinger to space the bit about $3.3 \mathrm{~m}$ outside the casing's guide shoe. The entire casing/stinger assembly was joined using the DrilQuip running tool and lowered through the moonpool at 1430 EST on 19 June.

The VIT was deployed soon after the pipe trip began. When the casing shoe had been lowered to about $1400 \mathrm{~m}$, it came into view on the TV monitor, but nothing could be seen extending below it. The obviously incorrect spacing indicated that a measurement error had occurred either for the casing string or the stinger. Both tallies were checked, but no error was found, so the entire assembly was brought back to the rig, and the casing string again was hung off in the moonpool. The running tool was removed from the stinger so that the drill string could be lowered through the casing. Visual monitoring with the TV indicated that $8.5 \mathrm{~m}$ needed to be added to achieve the correct relative spacing between the casing and the stinger. That was accomplished by adding drill pipe and drill-collar pup joints. The coring line sinker bar was lowered inside the stinger to land in the circulating sub, and the depth measurement indicated that the stinger had been too short and that the casing measurement was accurate. The pipe trip resumed at $0000 \mathrm{EST}$ on 20 June. 
Leg 156

Preliminary Report

Page 45

After reentry into the hole, the bit/underreamer was lowered to just above the casing shoe. Solid resistance was met at the casing shoe, with the "rathole" apparently closed in, and it was necessary to drill/underream from the shoe. Some difficulties (torquing up and slow progress) were encountered in opening the hole past the shoe/rathole area, but slow and steady progress then was established in drilling the casing ahead. Drilling/reaming parameters were $32.3 \mathrm{~L} / \mathrm{s}$ (500 gpm) circulation rate, approximately $145 \mathrm{rpm}$ on the PDM, and 4,500-11,400 kg $(10,000-25,000 \mathrm{lb})$ of weight applied. The first $38 \mathrm{~m}$ was made in $5 \mathrm{hr}$, and the operation was almost routine until a connection was made at 513 mbsf. The familiar sticking tendencies returned, and no further progress could be made. It appeared that the formation was squeezing the casing, inhibiting circulation and preventing weight from being applied at the bit/underreamer. It was necessary to make a short trip back above the casing shoe (where more torque and resistance were met going down). Nearly $20 \mathrm{hr}$ was required in reaming and back-reaming the hole through that interval before near-normal drilling parameters were regained and the resistance at 513 mbsf was passed. During that period, techniques were refined for the drilling-in operation. It was learned that better progress was made at somewhat-reduced circulation rates of $22.6-25.8 \mathrm{~L} / \mathrm{s}(350-400 \mathrm{gpm})$ and that getting restarted after connections involved pulling up a few meters before downward progress could be made. The casing was advanced from 513 to 528 mbsf in about $1.5 \mathrm{hr}$, but resistance again was met at 528 mbsf. Repeated attempts failed to advance the hole, and hydraulic resistance as well as sticking tendencies were met at that depth. Finally, additional weight was applied, and the pipe became firmly stuck.

Intervening events, including a check of drill-string length at the reentry cone during reentry and an additional check of the stinger tally, had convinced rig personnel that the original conclusion of a short stinger had been in error and that the casing was too long by $8.5 \mathrm{~m}$. All depths, including bit depth at the time of casing landing, then had been corrected, and the target bit depth had been established at 547 mbsf. Because the symptoms were so similar to earlier drilling difficulties, it was only after considerable effort, overpull, and 4-6 hr of pumping at high pressures and volumes had been applied to free the "stuck" pipe that it was suspected that the casing hanger might have latched in. A check against the pipe-length correction showed that $528 \mathrm{mbsf}$ was the correct landing depth for that assumption. The VIT frame then was lowered and provided visual confirmation that the casing hanger was down inside the reentry cone. String weight was slacked off until the casing string, $29,500 \mathrm{~kg}(65,000 \mathrm{lb})$, was supported by 
Leg 156

Preliminary Report

Page 46

the cone and surface casing. When torque was applied to the drill string, the DrilQuip running tool functioned perfectly and released after four quick revolutions of the pipe. A dense plume of effluent was then observed on the VIT image flowing freely from the reentry cone.

The actuating ball for the circulating sub then was dropped and allowed to free-fall in the pipe while the bit/underreamer was pulled above the screened section of the casing. It was then circulated into place at a low pump rate (so as to avoid actuation of the underreamer arms). The pin in the sub was sheared at $12.4 \mathrm{MPa}(1800 \mathrm{psi})$ to open the drill string to circulation above the PDM and to avoid a "wet trip."

Some drag and backflow were noted while the stinger BHA was being withdrawn from the casing string. That was attributed to packing of clay and cuttings around the lower BHA. When the BHA was recovered, those suspicions were borne out, as the two stands of drill collars near the bottom of the BHA were found to be tightly caked with clay.

To facilitate testing and flushing the PDM/underreamer with fresh water, the top drive was picked up. While the top drive was in place, it was blanked off and a pressure test of the rig's surface equipment was conducted in preparation for the forthcoming packer experiments. A logging/packer BHA then was assembled and tripped to reentry depth. Though the string-length discrepancy finally had been traced to a math error in the 12.7-cm (5") drill-pipe tally, the entire drill string was remeasured during the trip to dispel all doubts. A "pig" was inserted into the drill string, and the circulating head was attached to the top stand of drill pipe as it was picked up for reentry. While the vessel was maneuvered into position for reentry, the pig was pumped down the drill string to clean rust scale and pipe dope, which could interfere with the operation of the packer, from the interior of the string. Strong and variable currents interfered with positioning for reentry and over $4 \mathrm{hr}$ was consumed before a successful stab was made into the cone. It was noted that there was little or no flow from the hole at this time.

Upon reentry, the BHA was run into the hole, and knobby drilling joints were picked up in preparation for logging. The Schlumberger ASI was deployed for a second VSP in the lower section of cased hole. When the seismic array had been run to $240 \mathrm{mbsf}$, it unexpectedly came to a stop. The seismic array was light in weight, and an obstruction in cased hole had not been anticipated. Those factors resulted in the tool being "overrun," with excess slack put in the 
Leg 156

Preliminary Report

Page 47

cable immediately upon landing. When the ASI would go no deeper, it was function-tested with a few airgun shots and then retrieved to the surface. Some drag was noted during the retrieval, which became "jerky" at shallower depth. Upon recovery, the lower portion of the ASI was found to be knotted, with resultant severe kinking and abrasion. Subsequent repair and testing determined the array to be in operational condition.

The drill string then was lowered to check the obstruction. Resistance was met at $227 \mathrm{mbsf}$, and circulation was used to wash out the accumulation in the casing. After the second stand of pipe was circulated down, the hole was noted to be flowing vigorously with billowing clouds of sediment-laden water. It was inferred that the hole had filled in with sediment and that the obstruction had been cleared by the pipe. The top drive was picked up, and the BHA was circulated to total depth to ensure a clean hole for the packer experiments. Circulation was maintained while the string was advanced, and the slight drag noted was attributed to friction in the casing string and/or slight misalignment at the reentry cone. The hole was circulated at total depth for $30 \mathrm{~min}$ at $32.3 \mathrm{~L} / \mathrm{s}(500 \mathrm{gpm})$. As the string was raised to position the packer above the screened-casing interval, a drag of 9,100-13,600 kg (20,000-30,000 lb) was noted.

With the Tam Straddle Packer (TSP) positioned at 474 mbsf, near the center of the first casing joint above the screened interval, the instrumented go-devil was introduced into the pipe at the rig floor and pumped into place. The motion compensator then was activated and, upon landing of the go-devil, a sequence of permeability experiments was conducted. The initial setting of the TSP was routine, except that the expected "dump" of drill string pressure to the isolated formation interval below the packer was not reflected on the standpipe pressure gauges, only a slow decline in pressure. A good mechanical set was indicated by the weight indicator and behavior of the drill string, and the standpipe pressure steadied at about $1.4 \mathrm{MPa}$ (200 psi). Those factors indicated an otherwise-normal packer set, so the experiment continued without a reset. The first set of experiments involved "negative" pulses generated by opening the standpipe valve to bleed small amounts of water into the cementing tanks and then monitoring the aquifer's pressure recovery curves. It was noted that the pulses and recoveries were superimposed on a steady increase in shut-in pressure. The packer was found to be slipping during these tests, however, and only stopped when the element reached the depth of a tool joint in the casing. 
Leg 156

Preliminary Report

Page 48

With the initial series of tests complete, a wireline trip was made to retrieve the go-devil. When the data had been checked and determined to be of good quality, the go-devil was redressed and pumped back into place for a second series of tests. Positive pulse or "slug" tests, followed by a series of constant-rate injections, completed the permeability experiments, and a second trip with the coring line was made to retrieve the go-devil. The retrieval tool struck an obstruction in the drill pipe about $235 \mathrm{~m}$ above the TSP setting depth. Attempts to pass the obstacle were unsuccessful, and the wireline sinker bars were recovered. It was concluded that, because the hydraulic seal of the packer had not been broken completely, the go-devil had been unseated and forced up the drill string by material flowing from the formation. Failure of the retrieving tool to engage the go-devil was attributed to sand or debris in the pipe above the go-devil. A second run then was made with the coring line. The winch was stopped short of the previous set-down depth, the rams of the wireline BOP were closed, and pump circulation was applied until the pressure reading showed that the go-devil had returned to the packer. It was necessary to repeat that operation before the go-devil was engaged successfully for retrieval. When it was recovered to the surface, the go-devil assembly was clean and in good condition.

Because of the suspicion of sand/silt in the hole and because unobstructed hole was needed for the subsequent installation of the CORK sensor string, the coring line sinker bars were run back down the drill string and through the TSP into cased hole. The depth meter indicated that the sinker bars reached to within 3-4 m of total depth before setting down.

Upon recovery of the drill string, the TSP was noted to be in exceptionally good condition, although the element had not "relaxed" in diameter to the usual degree. The packer later was found to be filled with silt, sand, and clay, with sediment packed into the element, the control valve assembly, and all internal spaces. This meant that sometime before either the first or second packer set, mud must have been up inside the drill pipe above the go-devil seal and inflation ports.

The "stinger" for the CORK assembly was expanded to 12 used drill collars to provide sufficient weight to seat the CORK against a projected flowing pressure of at least 2.1 (and possibly 3.4) $\mathrm{MPa}$ (300-500 psi). When the stinger had been made up and hung off at the rig floor, the CORK and its running tool were assembled into the string. Two stands of drill 
collars above the running tool completed the BHA. After the pipe trip, a fairly routine reentry was made. Again it was noted that the hole had ceased flowing.

During the reentry operation, the wireline sinker bars had been run down to the BHA. As soon as reentry had been accomplished, they were run out into cased hole to recheck the amount of hole available for the CORK sensor string. The bars came to rest at $301 \mathrm{mbsf}$. It then became apparent that the hole was being infilled by the formation, and that sediment slurry had twice accumulated in the borehole until it had stopped the influx of water. It also was evident that the sensor string could not be emplaced under the existing conditions.

Few options were available, because the CORK assembly did not permit running the string into the hole or any circulation beyond the running tool. Setting a 300-m sensor string was scientifically unacceptable, so it was necessary to trip the drill string before any further action could be taken. As no casing plugs were available, the best chance of successfully emplacing a full-length sensor array was judged to involve "killing" the hole with weighted drilling mud to arrest the influx of sediment-laden water. Because that action would consume most of the remaining stock of barite, however, operational capabilities for the subsequent site would be compromised.

A round trip of the drill string was made, the CORK assembly was laid out, and reentry was made with an open-ended BHA of two stands of drill collars. The hole was "washed" clean without difficulty from the top of fill, which had risen to $231 \mathrm{mbsf}$. To avoid the possibility of reopening the casing/hole annulus to flow, the reentry/cleanout bit was positioned $4 \mathrm{~m}$ above the casing shoe for hole conditioning by circulation. The decision was reached to commit the heavy mud to the successful completion of Hole 948D and mixing of the fresh-water/ bentonite/barite suspension to $1.6 \mathrm{~kg} / \mathrm{L}$ (14 lb/gal) began. After the bit had been advanced to total depth and after a total of $10.5 \mathrm{hr}$ of circulation, the hole was displaced with $57,000 \mathrm{~L}$ ( 350 bbl) of mud. The BHA then was pulled back to $92 \mathrm{mbsf}$, where the trip was interrupted for slipping and cutting the drilling line. No flow from the cone occurred while the hole was observed by TV for $1 \mathrm{hr}$ during that operation.

Again the drill string was tripped, and the stinger (shortened to four drill collars) and CORK assemblies were incorporated into the BHA. Reentry was made with the stinger after 45 min of 
Leg 156

Preliminary Report

Page 50

positioning, and the coring line sinker bars, which had been run to the upper BHA, were lowered into the cased hole. The bars descended unimpeded to total depth, indicating that the hole was ready to receive the full CORK sensor string.

The string of thermistors and pressure transducers provided by IFREMER had been prepared for deployment, and the drill floor was rigged for handling the string. Initial handling of the sensor array was straightforward, as the spacing of the instrument nodes provided attachment points that enabled the crew to handle $25-\mathrm{m}$ sections of the string. The sensors were spaced at $50-\mathrm{m}$ intervals in the upper portion of the string, which entered the pipe last. That spacing exceeded the working height in the derrick, and it was necessary to use a large sheave so that the cable could be handled in a doubled configuration. Two 50-m sections of the cable were damaged by a sharp edge on the sheave frame when tension was transferred between handling winches. The damaged sections were replaced with spare sections totaling $85 \mathrm{~m}$ in length and, after $5.5 \mathrm{hr}$, the array was hung off in the drill pipe. A 10.2-cm (4") overshot then was used to connect the sinker bars of the coring line to the data logger at the top of the array for lowering.

To avoid "floating" or damage to the sensor string, the load was lowered slowly and cautiously. The weight indicator showed that the data logger had landed approximately at the proper depth, but depth and tension indications were ambiguous owing to the length/weight of the line and to vessel motion. Because the normal amount of overpull required to shear the pins to release the overshot was not seen, numerous attempts were made to latch the data logger into the CORK, with some attempts involving downward jarring with the sinker bars. It finally was decided that some weight had been lost (but less than the weight of the sensor array), and the coring line was retrieved. Upon its arrival on deck, the overshot was found to have released the array and the pin to have sheared. To verify that the data logger was latched in, the redressed overshot was run back to engage the data logger. Upon landing the overshot, an overpull of $1,800 \mathrm{~kg}(4000 \mathrm{lb})$ was taken before the pin was sheared by jarring, and the wireline again was recovered.

The top drive then was picked up, and knobby drilling joints were added to land the CORK in the reentry cone. With the CORK landed and the motion compensator in operation, the 10.2-cm-diameter (4") setting ball was dropped and pumped down to the running tool. When the ball landed, the pump was stopped momentarily with drill-string pressure holding at 1.7 
Leg 156

Preliminary Report

Page 51

$\mathrm{MPa}(250 \mathrm{psi})$. Pressure then was increased to $6.9 \mathrm{MPa}$ (1000 psi) to be held for $20-40 \mathrm{~s}$ to actuate the hydraulic latching mechanism. After only a few seconds, however, pressure abruptly fell to zero. The probable cause of the premature release of pressure was considered to be shearing out of the seat in the running tool at less than the design pressure of $12.4 \mathrm{MPa}$ (1800 psi). On the slim chance that the ball had become temporarily fouled at a tool joint or other pipe restriction, circulation was continued for several minutes with no results. A final attempt to latch was made by pumping a second ball down the drill string, again with no pressure indication of landing. While further actions were considered, the wireline sinker bars were run to confirm that the balls had reached the depth of the running tool.

Inability to achieve mechanical latching left only two operational choices. The CORK could be released with only the weight of the stinger and CORK to maintain the seal by gravity or the entire CORK and sensor-string assembly could be recovered to the drill floor, the sensor string removed, the running tool redressed, and the entire deployment procedure repeated. The principal drawback to the former choice was that the hydraulic seal of the CORK would be lost if/when the hole pressure at the CORK exceeded hydrostatic pressure by more than the pressure exerted by the CORK (about 1.0 MPa [145 psi], probably less than half the greatest formation overpressure at the middle of the screen). In addition to the impact of the latter option on operating time and remaining scientific objectives, there was a very high risk of damage to the French sensor array in pulling it clear of the reentry cone. We could not retrieve the IFREMER string without first bringing the CORK back to the ship, because the setting balls prevented engaging the data logger with the wireline. After the alternatives had been considered, the decision was made to release the CORK and to continue with the operational plan of the leg. The final configuration of the IFREMER sensor string in Hole 949D is listed in Table 3 and is shown relative to casing and screen positions in Figure 1.

The moonpool doors were opened, and the ROV landing platform was installed around the drill string and free-dropped. Immediately, the VIT was installed and run down the pipe to observe the position of the platform and the unjaying operation. When the VIT arrived at viewing depth, the platform was seen to be slightly off center, so the CORK was raised out of its seat sufficiently to reposition the platform. The CORK then was reseated, the drill string was slacked off and turned slightly to the right, and the CORK assembly was released. 
Leg 156

Preliminary Report

Page 52

During the final pipe trip at Site 948, both "live" positioning beacons were recovered. Attempts were made to call up a third beacon, which had ceased transmitting several days earlier, but the beacon did not surface. As plans to occupy site NBR-3 had been canceled, the vessel was offset to that location during the trip to reactivate and recover the beacon launched there on 28 May and subsequently switched to standby mode. No response was received from that beacon, and it failed to surface.

\section{Site 949}

Because of the numerous unforeseen delays at Site 948, insufficient operating time remained to complete the full planned program at Site 947 (NBR-3). For that reason and because Site 947 promised to be even more difficult operationally than Site 948, plans for a CORK installation there were abandoned. A new site, NBR-7, was proposed and approved to provide an opportunity to penetrate the décollement in a similar geological setting as Site 949 but at a shallower depth. The new site is located about $2.4 \mathrm{~km}$ northeast of Site 948 and $3.9 \mathrm{~km}$ east-northeast of Site 947 . A positioning beacon was launched on GPS coordinates at 1615 EST (local time), 29 June to begin operations at Site 949.

\section{Hole 949A}

When the APC/XCB bottom-hole assembly (BHA) had been run to the seafloor, a "mud-line" APC core was taken to determine seafloor depth. The corer was actuated at $5014 \mathrm{mbrf}, 2 \mathrm{~m}$ above the PDR depth. Core recovery from the $9.5-\mathrm{m}$ stroke was $2.95 \mathrm{~m}$ and fixed seafloor depth at 5020.5 mbrf.

A jetting test for conductor casing-setting depth then was performed. The sediment was somewhat less firm than at Site 948 , and it was determined that a minimum of $56 \mathrm{~m}$ of conductor casing could be jetted into the seafloor. Maximum parameters used for jetting were $17.7 \mathrm{~L} / \mathrm{s}$ ( $275 \mathrm{gpm})$ and $9,000 \mathrm{~kg}(20,000 \mathrm{lb})$ weight-on-bit (WOB). When the test had been completed, the bit was pulled clear of the seafloor and the jetting core barrel was retrieved.

\section{Hole 949B}

During the wireline trip, the vessel was offset $125 \mathrm{~m}$ south and $30 \mathrm{~m}$ east, and a core barrel equipped with a center bit was pumped into place at the bit. When stable positioning had been achieved, the bit was lowered until a weight indication was seen on the driller's gauge, 
Leg 156

Preliminary Report

Page 53

establishing the seafloor depth at 5024 mbrf. Spud time was 0545 EST on 30 June. The 11-7/16" hole was drilled ahead without coring to 244 mbsf in just over $7 \mathrm{hr}$, after which the wash barrel was recovered and an XCB core barrel pumped into place. Continuous coring then began.

Core recovery was variable, ranging from 0 to $102 \%$ and averaging $40 \%$. Some cores appeared to have been lost owing to stuck-open core catchers, but in most cases the liners showed no traces of mud inside, indicating that core had never entered the chamber. Various combinations of drilling parameters and core catchers were tried with no consistent results.

Coring was interrupted at 263, 312, and 350 mbsf for water-sampling temperature probe (WSTP) runs, in temperature-only mode. In anticipation of potential hole-closure problems, such as had occurred in other holes drilled in the region, a "precautionary" wiper trip was made back to 311 mbsf after the hole had been advanced to 399 mbsf. When the coring depth objective was reached, enough core had been recovered to convince researchers that the décollement had been crossed, but recovery was insufficient to reveal its nature or exact depth. Absolutely no hole trouble had been experienced until some minor torquing and overpull occurred after the final XCB core (Core 156-949B-24X) had been laid out from 456 mbsf. A final WSTP temperature run then was made at 456 mbsf.

Following the WSTP run, one final effort was made to obtain an APC core adequate for age dating and identification of lithologic units. While the APC coring assembly was run down the drill string, $2 \mathrm{~m}$ of new hole was drilled so that any core obtained would not be affected by disturbance from the WSTP probe. When the APC was fired, an incomplete-stroke indication was noted, but the barrel was withdrawn without excessive overpull. A 5.1-m core was recovered, of which about $50 \%$ was later determined to be flow-in disturbance.

Hydrologic interference with the nearby planned sealed reentry hole was a concern, and a borehole plug was requested. After the core bit had been pulled to $321 \mathrm{mbsf}$, cement slurry was mixed to $1.9 \mathrm{~kg} / \mathrm{L}$ (15.5 lb/gal) and emplaced from 321 to $101 \mathrm{mbsf}$. The pipe was then pulled clear of the seafloor, flushed of cement residue, and tripped to the surface, ending Hole 949B at 0915 EST on 3 July. 
Leg 156

Preliminary Report

Page 54

\section{Hole 949C}

For the reentry installation at Hole 949C, an identical hardware configuration to that of Hole 948D was used, except for the addition of a 4-m "cutoff" casing joint.

During the trip to install the reentry cone and conductor casing, the ship was moved back toward the offsets of Hole 949A. At 0645 EST on 4 July, Hole 949C was spudded as jetting of the conductor casing began. Jetting was slowed by the unfavorable hydraulics of the bit/underreamer combination, as at Site 948, but sediments at this site were softer. To avoid excessive erosion of the casing/hole annulus, the circulation rate was held to a maximum of $21 \mathrm{~L} / \mathrm{s}$ (325 gpm). Slow, steady progress was made for about $3-1 / 2 \mathrm{hr}$ until the casing shoe reached $5062.5 \mathrm{mbrf}, 4.5 \mathrm{~m}$ short of the target depth based on the Hole 949A mud-line core. Even with full casing/cone weight applied, no further progress could be made, and it was decided to release the assembly at that depth.

Operation of the DrilQuip running tool was routine, and, as soon as the underreamer arms were advanced past the casing shoe, the circulation rate was increased to $45.2 \mathrm{~L} / \mathrm{s}$ (700 gpm), and drilling of a 44.4-cm (17-1/2") hole began. A good rate of penetration (ROP) was maintained, and the hole was drilled to the target depth of $398 \mathrm{mbsf}$ in 8-1/2 hr. Before the round trip for casing began, the hole was filled with mud with an average weight of $1.5 \mathrm{~kg} / \mathrm{L}(12.8 \mathrm{lb} / \mathrm{gal})$.

When the BHA for running 40.6-cm (16") casing had been dismantled, the running tool for 34.0$\mathrm{cm}$ (13-3/8") casing was made up to a stand of drill collars, and tools were assembled for running the surface-casing string. Thirty joints of range-3 34.0-cm (13-3/8") casing were then assembled, with the casing hanger as the final joint. It was necessary to restrain the casing in the moonpool area with tugger lines and to fill it often with water to combat the effects of currents on the casing suspended below the ship. The casing-running tool, with cementing plug attached, was made up to the casing string, and the casing was run to reentry depth with the drill string filled each 20 stands. The first reentry into the Hole 949C cone required over $4 \mathrm{hr}$ of maneuvering because of a combination of unfavorable currents, unfamiliarity with the orientation and "location offsets" of the cone, and marginal sonar performance. At the time of reentry, it was confirmed, by pipe measurement and video inspection, that the cone had remained at the depth at which it was released and that the mudskirt was landed at the seafloor. (A check of navigation records revealed that the Hole 949C cone actually had been emplaced about $30 \mathrm{~m}$ in an upslope direction from Hole 949A.) 
Leg 156

Preliminary Report

Page 55

When the casing had been run to $89 \mathrm{mbsf}$, resistance was noted on the weight indicator. It was not apparent whether the weight was being taken by obstructed hole or the effect was merely buoyancy of the casing in heavy mud, but the top drive was deployed and the casing was "washed" in through the remaining hole interval.

No difficulty was encountered in advancing the casing with the top drive and fluid circulation. As at Hole 948D, returns were noted to be reaching the seafloor via the conductor casing/hole annulus. As the casing shoe was lowered, with circulation, to its setting depth, no fill or resistance was noted, indicating a clean hole. Surprisingly, the string was lowered through the expected landing point with only a momentary indication of "taking weight." No further change in string weight was seen until the casing was set down abruptly when the shoe reached $5414.2 \mathrm{mbrf}$, which coincided exactly with the total depth of the hole. The string was raised to check for latch-in of the casing hanger. A 9,000-kg (20,000-lb) overpull was taken, and the TV picture showed relative motion between the pipe and the reentry cone. To avoid disturbing the minimal reconstitution of sediment around the conductor casing, no additional tension was applied.

The discrepancy of about $7.5 \mathrm{~m}$ between the depth of the 34-cm (13-3/8") casing hanger and its intended seat was disturbing because that spacing was critical in placing the seal sub of the subsequent 27.3-cm (10-3/4") casing string opposite the sealing bore of the 34-cm (13-3/8") casing hanger. The vertical dimensions were known exactly with all three components latched together, but there was considerable uncertainty with the 34-cm (13-3/8") string below its seat and sitting on the bottom of the hole. Without a positive annular seal, the packer-permeability experiments and long-term CORK pressure monitoring would be either compromised seriously or completely ineffective. There was also concern that the 34-cm (13-3/8") casing, when set in compression, would begin to buckle and "helix" in the hole to the extent that the $27.3-\mathrm{cm}$ (10-3/4") string (or the 31.1-cm (12-1/4" bit) would not pass through it. To compound the riddle, the nature of the failure was not understood. Without a major dimensional error in one or both components, it should not have been possible for the casing hanger to pass through its seat in the adapter sub. That left the possibility that the 40.6- $\mathrm{cm}$ (16") casing had parted below the reentry cone and had either fallen down the 44.5-cm (17-1/2") hole or been pulled down with the 34-cm (13-3/8") string after engagement. 
Leg 156

Preliminary Report

Page 56

Because there was resistance to raising the casing string from its position, there was little choice but to proceed with cementing and releasing the casing at that depth. A special lightweight cement slurry was mixed to $1.7 \mathrm{~kg} / \mathrm{L}$ (14 lb/gal) using $1.2 \%$ (by weight) bentonite prehydrated in freshmix water. The slurry was pumped into the drill string, circulation then was switched to the mud pump, and the cement was displaced with seawater. Circulating pressure built only to $3.8 \mathrm{MPa}$ (550 psi) during the displacement and failed to rise during the final phase of displacement, again indicating that the formation had broken down and cement had not filled the entire annular column. No returns could be seen by TV either inside or outside the reentry cone during the entire cementing/displacing operation. When the top plug "bumped," the standpipe bleedoff valve was opened. Only a brief backflow was noted, indicating that the float valve in the casing shoe was holding and that cement slurry was not flowing back inside the casing.

A round trip and routine reentry then were made for a 31.1-cm (12-1/4") bit and drilling BHA. The bit traveled unimpeded past the 34-cm (13-3/8") casing hanger and through the entire casing string, allaying concerns about parted 40.6-cm (16") casing, an off-center casing hanger, or "helixed" casing. No resistance whatever was encountered down to $5413 \mathrm{mbrf}$. The plug and shoe were drilled out in just $1 \mathrm{hr}$. Three meters of new hole then was made, and the hole was flushed with extra-high-viscosity mud to clear it of debris.

The bit was pulled clear of the reentry cone and released onto the seafloor. During the tripping and releasing operations, the VIT had been run to reentry depth, so that another routine reentry put the drill string into logging position. Logging sheaves then were rigged, and the cement-bonding log (CBL) tool was made up to the logging cable and run down the pipe.

Results of the CBL showed that fairly good cement bonding extended over the lowermost $40 \mathrm{~m}$ of the casing string, and there was evidence of cement up to $108 \mathrm{~m}$. Indications of signal from the 40.6-cm (16") casing collars and shoe were seen through the uncemented 34-cm (13-3/8") casing and indicated that the 40.6- $\mathrm{cm}$ (16") string was in its proper position. An interval of several meters of low-amplitude signal between the 34-cm (13-3/8") hanger and the point where the CBL enter the drill string originally was interpreted as open hole, but later was concluded to be the effect of centralization and the distance to the 40.6-cm (16") pipe. 
Leg 156

Preliminary Report

Page 57

Upon recovery of the CBL, it was replaced with the Schlumberger Array Seismic Imager (ASI), which was lowered a short distance down the pipe. The traveling block then was raised to its highest position, pulling the end of the drill string about $22 \mathrm{~m}$ clear of the reentry cone. In preparation for deployment of explosive charges, all sources of electromagnetic radiation and extraneous electrical fields were secured.

The vessel then was offset about $1200 \mathrm{~m}$ to the northwest to begin deployment of charges for the shear-wave VSP (SWVSP) experiment. In total, 21 charges were laid in a fan-shaped array to the north of Site 949. Because it was necessary to maintain ship's heading into the current to carry the charges clear of all propellors, the explosives were deployed in three subparallel traverses that were roughly west-to-east. Despite some positioning complications from variable currents and threats of rain showers, conditions remained generally favorable, and the deployment was completed in $11 \mathrm{hr}$.

When the last of the explosives had been released, the vessel returned to normal operating mode, offset back to Hole 949C, the VIT (which had been held just below the ship) was lowered down the drill string, and the ASI was lowered down the inside of the pipe. A quick reentry was made and the ASI was run into open hole. Because deployment and reentry had gone smoothly, about 5 $\mathrm{hr}$ was available before detonations were scheduled to commence. Air guns and hydrophones were rigged so that shooting could begin on the scheduled standard VSP. The first (lowermost) station of the VSP was completed prior to interruption for the SWVSP.

About $1 \mathrm{hr}$ before explosive detonations were to begin, the Schlumberger seismic system was converted to the mode for recording the SWVSP. The first charge failed to detonate, but 19 of the remaining 20 shots were successfully heard and recorded over the ensuing $4 \mathrm{hr}$. Recording of the standard VSP then resumed and was completed in the next 5-1/2 hr. The ASI was recovered, the logging sheaves were rigged down, and the pipe was tripped by 2200 EST on 9 July.

Because of the detachment of the surface casing string, accurate measurements were needed to adjust the spacing of the seal sub in the 27.3-cm (10-3/4") casing string. The casing string was to be landed in the reentry cone, but the seal sub had to mate with a reduced-diameter section in the 34-cm (13-3/8") casing hanger that was only 16 " in vertical length. To obtain the needed 
Leg 156

Preliminary Report

Page 58

measurements, a dedicated round trip was made with a BHA featuring the 40.6-cm (16") DrilQuip running tool with the 34-cm (13-3/8") running tool directly beneath it.

During preparations to deploy the VIT, the reentry sonar was found to be nonoperational. There was little prospect for repair in a reasonable time period, so the VIT was run with only the TV operational. The ensuing reentry required $6 \mathrm{hr}$ because the reentry cone could not be tracked outside the television's field of view, which is about $15 \mathrm{~m}$ in diameter.

When reentry finally was accomplished (with the top drive), the drill string was lowered a few meters until the 40.6-cm (16") running tool landed in the 40.6-cm (16") casing hanger. With the motion compensator holding about $2300 \mathrm{~kg}(5000 \mathrm{lb})$ weight down on the hanger, the pipe was marked at the rotary table. The string then was rotated to the right to release from the running tool bushing and allow the string to advance until the 34-cm (13-3/8") running tool found its seat in the other casing hanger. Left-hand rotation was used to engage the casing hanger, and tension was taken to verify that the running tool had reached the seat in the hanger. After $2300 \mathrm{~kg}(5000 \mathrm{lb})$ again had been applied, a second mark was made on the pipe, and the running tool was released with clockwise rotation. Because the dimensions of all hardware components were known, the distance between the marks provided the needed information to determine that the $27.3-\mathrm{cm}$ (10-3/4") seal sub needed to be spaced $7.04 \mathrm{~m}$ lower than normal. The drill string then was tripped for a coring BHA.

In an attempt to supplement the low core recovery of Hole 949B through the zone of greatest scientific interest, an RCB BHA was assembled to core the interval below the surface-casing shoe and extending through the décollement. The combination of the RCB coring system and the anti-whirl polycrystalline diamond compact (PDC) core bit was chosen because it had outperformed the other rotary systems in terms of core recovery and quality on recent legs.

Reentry was made in $1-3 / 4 \mathrm{hr}$ with the aid of a barely functioning sonar. No resistance was met as the bit was run to total depth $3 \mathrm{~m}$ below the casing shoe, where continuous RCB coring commenced.

Seven cores were attempted over an interval of $62.8 \mathrm{~m}$ (401.0-463.8 mbsf). Unfortunately the coring performance was even worse than with the XCB system in Hole 949B; average core 
Leg 156

Preliminary Report

Page 59

recovery was only $3.5 \%$, with several zero-recovery cores. Again, various combinations of coring parameters, core catchers, etc., were tried without success. Core 949C-7R had the highest recovery (11.4\%), and was of the more-recoverable lithology recognized to be from below the décollement. Further coring was judged to be of little value, and the drill string was tripped for the third casing string.

During the coring operation, the necessary hardware changes had been made to produce a "production" casing string with an annular seal. A joint of casing had been cut to length and welded onto the 27.3-cm (10-3/4") casing hanger to extend it from its standard length of 1.45 to $8.49 \mathrm{~m}$. Also, the seal sub had been modified by adding more seal grooves and seals to increase the length over which an effective seal could be achieved.

The total string, including 34 joints of casing, the seal sub, and the hanger, was assembled in $8 \mathrm{hr}$. The four joints immediately above the shoe joint were special perforated joints covered with a gravel-pack screen. An additional $5 \mathrm{hr}$ was required to make up the "stinger" BHA terminated by the PDM and underreamer. After the trip to reentry depth, reentry was made in 1-1/4 hr with sonar performing at a marginal level. During reentry, the arms of the underreamer were noted to be in a partially open position.

Following reentry, the bit/underreamer assembly would not pass the approximate depth of the 34$\mathrm{cm}$ (13-3/8") casing hanger. It was difficult to determine whether the edge of the hanger was being contacted by the underreamer arms or by the sharp-edged casing shoe because of their close spacing. After other attempts failed, it was necessary to pick up the top drive and rotate the entire string slowly to the left as it was lowered past the hanger to move the edges past the obstruction.

The casing string was run to $371 \mathrm{mbsf}, 27 \mathrm{~m}$ above the surface casing shoe, before the top drive was picked up. No resistance had been felt to that point, but the drill string was found to be plugged when circulation was attempted. More pipe was added to advance the bit below the casing shoe, where full pump circulation could be applied without concern of opening the underreamer. "Soft" fill was encountered within a few meters, however, and the string was stopped about $4 \mathrm{~m}$ short of the shoe. When additional attempts to unplug the drill string were unsuccessful, the pipe was pulled back to the reentry cone in the hope that it would be cleared by the surge of tripping. The string remained blocked, so the pipe was swabbed at the surface with a wireline swab cup in a 
Leg 156

Preliminary Report

Page 60

final attempt to establish circulation by applying a negative pressure differential across the bit. The efforts did not succeed, and a round trip was necessary to clear the pipe. It was a slow trip because it was "wet," with $30 \mathrm{~m}$ of water gushing from each stand of pipe as its connection was broken.

When the BHA arrived at the rig floor, the casing string was detached and hung off in the moonpool. The stinger then was recovered, and muddy water was found in the pipe more than $300 \mathrm{~m}$ above the bit. As more BHA components were set aside, sand and silt had to be cleaned from the lowermost few meters above the PDM, and the upper portion of the PDM was found to be packed with clean, fine "sugar" sand. About $2 \mathrm{hr}$ was required to clean the sand from the motor and to restore normal operation.

During the recovery pipe trip, adapters had been fabricated in the rig's machine shop to fit a float valve to the cavity of a coring top sub. The improvised float sub was placed above the PDM when the BHA was reassembled, with a $305-\mathrm{cm}\left(10^{\prime}\right)$ drill pipe pup joint replaced by a $152-\mathrm{cm}\left(5^{\prime}\right)$ pup to preserve spacing. In addition, the underreamer arms had been taped in the closed position to avoid fouling on the 34-cm (13-3/8") casing hanger. The casing string then was reattached to the BHA and run back to reentry depth at a slower-than-normal pace because of the requirement to fill the pipe periodically (imposed by the float valve). With the sonar completely inoperative, the TV-only reentry consumed 4-3/4 hr.

Again, the lower assembly failed to pass the 34-cm (13-3/8") casing hanger, and it was necessary to use the top drive to "rotate past" the shoulder. The casing shoe was lowered to 345 mbsf before the top drive was deployed. When fill was tagged at $374 \mathrm{mbsf}$ ( $24 \mathrm{~m}$ inside the surface casing), slow circulation of $6.5 \mathrm{~L} / \mathrm{s}(100 \mathrm{gpm})$ was used to turn the PDM and wash out the fill without opening the underreamer arms. At 400 mbsf, the underreamer was in open hole, and the circulation rate was increased to clean the hole and drill/ream ahead.

The drilling-in operation with casing proceeded remarkably smoothly over the interval of the pre-drilled (cored) hole, with little weight required and a high ROP. The casing shoe was advanced from 401 to $463 \mathrm{mbsf}$ in only 1-1/2 hr. An additional 2-3/4 hr was required to penetrate the final $2.5 \mathrm{~m}$ and land the casing hanger in the 40.6- $\mathrm{cm}(16 ")$ hanger. During that interval, the casing began to "pack off," and weight and depth indications became ambiguous. The assembly appeared to be landing at a point about $2 \mathrm{~m}$ short of the expected depth, but latch-in was not 
Leg 156

Preliminary Report

Page 61

achieved because the casing string could be pulled free--indicating that the snap ring of the casing hanger had not engaged. Circulating pressure increased whenever the string was lowered and appeared to hold formation pressure with the pump stopped. It could not be determined whether that was the effect of the hole packing off or of the annular seal sub reaching its seat in the 34-cm (13-3/8") casing hanger. On two or three occasions, the casing was believed to be latched in, and attempts were made to release it. Those resulted only in apparent rotation of the entire casing string and freeing it vertically. Finally, weight $(36,000 \mathrm{~kg} ; 80,000 \mathrm{lb})$ far in excess of the casing weight was set down, and all aspects of latch-in were noted.

Releasing the casing string also proved difficult. Weight approximately equivalent to that of the casing was set down and rotation was attempted, but the string would not rotate. High torque was held on the string while string weight was varied to find the "neutral point." Only after the seemingly excessive weight of $36,000 \mathrm{~kg}(80,000 \mathrm{lb})$ was set down did the drill string spin free and separation occur.

As the pipe trip began, the actuation ball for the circulating sub was dropped and allowed to fall until the seafloor was cleared. Pressure then was applied to open the sub and allow the trip to continue "dry." Upon recovery and disassembly of the stinger BHA, the PDM and underreamer were flushed with fresh water by circulation through the top drive. Before the top drive was set back, it again was blanked off for a test of rig surface equipment to $15.2 \mathrm{MPa}(2200 \mathrm{psi})$ in preparation for the permeability experiment.

To complete the casing installation for the final phase of experiments and emplacement of the CORK sensor string, blockage of the bottom of the casing was desired. A mechanical-set packer, or bridge plug, had been delivered by helicopter for that purpose. The bridge plug and its running tool were attached to a BHA of three drill-collar stands and a drilling jar. Because of the possible presence of sand in the hole, the improvised top/float sub also was included. The pipe trip again was slowed for filling the pipe, but a 15-min reentry was made with the aid of a repaired sonar tool.

When the bridge plug had reached $382 \mathrm{mbsf}$, the top drive was picked up. At $410 \mathrm{mbsf}$, an obstruction was contacted. Some fill had been anticipated and the plan was to wash the plug to just above the casing shoe with pump circulation. However, circulation proved completely ineffective 
Leg 156

Preliminary Report

Page 62

at removing the blockage or advancing the plug downhole. Pump rates as high as $54.9 \mathrm{~L} / \mathrm{s}(850$ gpm) were tried, with weight to $11,000 \mathrm{~kg}(25,000 \mathrm{lb})$ applied (rotation was not an option with the rotation-set plug.) Progress was barely measurable. After more than $2 \mathrm{hr}$ of pumping and working the unfamiliar plug in the hole, attempts at cleaning the hole were abandoned in consideration of the possibility of junking it. At that time, the nature of the very-solid obstruction was questionable, and failure of the plug or running tool was considered to be possible. The bridge plug was tripped back out of the hole.

At 0330 EST on 17 July, the bridge plug arrived on the rig floor. It was in excellent condition, but the concave base was packed solid with a mixture of clay, silt, and fine sand. Embedded in the sediment were several large chunks of black rubber, apparently pieces of the plugs used on the surface-casing cement job. The sediment was a positive indication that the impediment was fill and not a mechanical problem with the casing, plug, or running tool. Unknowns included the reason for the inability to circulate out the relatively soft sediment, the mechanism by which the rubber found its way to the top of the fill, and the route by which sediment had entered the casing. Several options for the next step were considered before a tricone drill bit was made up to a short $\mathrm{BHA}$ and run in to clean out the hole.

During the pipe trip, the design of the lower portion of the bridge plug was studied, and additional information about it came to light. It became apparent that the lowermost portion, an integral "junk pusher," was designed to retain debris in the hole below the plug when fluid circulation is used by means of a hydraulic "curtain" formed by the location and attitude of the jet nozzles and by the skirt beneath them. To provide the capability of "washing" through sediment in the hole, the plug was modified in the ship's machine shop. The skirt was removed with a hacksaw, and short lengths of pipe were welded into the nozzle ports to orient them vertically and extend them to the bottom of the plug.

Even with the sonar operational, reentry took 2-1/4 hr. No sign of flow from the hole was noted. The top drive was picked up when the bit had been lowered to $374 \mathrm{mbsf}$, and fill was contacted at $395 \mathrm{mbsf}, 11 \mathrm{~m}$ higher than on the previous day.

Only $1 \mathrm{hr}$ was required to wash the fill from the hole with a 200 -gpm pump rate and no rotation. The bit was stopped $2.5 \mathrm{~m}$ above the casing shoe to avoid washing out any material that might be 
Leg 156

Preliminary Report

Page 63

plugging the annulus around the shoe. A 20-bbl sweep of sepiolite drilling mud was circulated through the hole to ensure complete cleaning before the drill string was withdrawn. The bit was back on deck at 0500 EST on 18 July.

With the modified bridge plug, the pipe again was run back to reentry depth. Just as the search for the reentry cone began, the underwater television signal was lost. Good sonar function was retained, but it was considered too risky to attempt a sonar reentry with the somewhat-fragile castiron bridge plug. In all, 4-3/4 hr was spent in recovering the VIT, troubleshooting and rectifying the TV problem, and running the VIT back to reentry depth. Upon recommencing the search for the cone, the sonar failed. The tedious TV-only reentry then required an additional 2-1/4 hr, during which time the hole appeared to be flowing.

After the top drive was deployed at $378 \mathrm{mbsf}$, fill was found at $431 \mathrm{mbsf}$, with just $32 \mathrm{~m}$ of sediment accumulating in the $27 \mathrm{hr}$ since cleanout. The modified plug was an improved wash-down tool, and the hole was cleaned to plug-setting depth at $463 \mathrm{mbsf}$ in 1-1/4 hr. After 35 clockwise revolutions to set the upper slips, tension was applied in $6800-\mathrm{kg}(15,000-\mathrm{lb})$ and $14,000-\mathrm{kg}(30,000-\mathrm{lb})$ steps to set the mechanical packer element and the lower slips. Tension then was increased to $23,000 \mathrm{~kg}(50,000 \mathrm{lb})$ to part the tension sleeve and release the plug. To augment the mechanical locking and verify integrity, a BHA weight of $11,000 \mathrm{~kg}(25,000 \mathrm{lb})$ was set down on the plug momentarily. Fifteen minutes of seawater circulation at $32.2 \mathrm{~L} / \mathrm{s}(500 \mathrm{gpm})$ with the pipe at $460 \mathrm{mbsf}$ then cleaned the casing/pipe annulus before the drill string was pulled.

As soon as the plug running tool and float sub had been removed, the logging/packer BHA was assembled and run to reentry depth. A $2 \mathrm{hr}$ TV-only reentry was made into a cone that showed no sign of flow. The TAM straddle-packer (TSP) was run to $376 \mathrm{mbsf}$, where the top drive was deployed.

Permeability tests began with the dropping of the instrumented inflation go-devil at 2015 EST on 19 July. While the go-devil was pumped down the pipe, the TSP was positioned at $392 \mathrm{mbsf}$, and the motion compensator was actuated. A series of successful measurements were in the concluding stages when the packer began to "climb" in the hole. Apparently it was losing inflation pressure and was being pushed up the hole by confined test pressure. After the TSP was unseated and the go-devil retrieved for data, the coring-line sinker bars were run to test hole depth and found $15 \mathrm{~m}$ 
Leg 156

Preliminary Report

Page 64

of fill. While data were being checked, the drill string was lowered, with circulation, to $3 \mathrm{~m}$ off the plug to wash the fill from the hole. After $30 \mathrm{~min}$ of circulation at $19.4 \mathrm{~L} / \mathrm{s}$ ( $300 \mathrm{gpm})$, the TSP was pulled back to setting depth above the screened casing interval. The second packer set was at 388 mbsf, just below a casing connection that it was hoped would retard slippage of the element up the hole. Several tries were required to obtain a good set, as the element was sealing hydraulically and vessel heave caused the sliding control valve to dump pressure into the borehole. When a satisfactory set was achieved, it held through $2 \mathrm{hr}$ of testing before it again began to climb during a constant-rate injection test. The full BHA weight of $14,500 \mathrm{~kg}(32,000 \mathrm{lb})$ was required to hold the packer down while pressure was monitored. It was necessary to bleed off drill-string pressure at the standpipe to unseat the packer, because trapped pressure in the borehole pushed it up the hole when the pipe was raised. The go-devil arrived on deck at 1530 EST on 20 July to conclude the packer experiments.

In preparation for the VSP operation, 10 stands of drill pipe were laid out to raise the BHA to just below the seafloor. A second "sounding" was taken with the sinker bars, and no hole fill was encountered. The logging sheaves were rigged, and the Schlumberger ASI tool was deployed for an air-gun VSP over the cased-hole section below the surface casing. Most of the $12 \mathrm{hr}$ consumed by the VSP was in rigging and running the ASI. Air-gun shots were recorded at stations in the interval below the surface-casing shoe, which had not been drilled at the time of the earlier VSP. The logging sheaves were rigged down while the coring-line sinker bars again were run to check hole fill. The bars came to rest at 458 mbsf, just $4 \mathrm{~m}$ short of the bridge plug by depthometer measurement.

The drill string was recovered, and the rig was prepared for the final phase of site operations. A "stinger" BHA of three used 8-1/4" drill collars and five used 7-1/2" drill collars was assembled and hung off at the rig floor. The CORK and its running tool then were incorporated into the drill string, and an upper BHA of two stands of drill collars completed the assembly.

Following the trip to the seafloor with the CORK assembly, another television-only reentry consumed 2-1/4 hr. The end of the stinger was run $58 \mathrm{~m}$ into the hole, where it was held for the installation of the sensor string and data logger. 
Leg 156

Preliminary Report

Page 65

A final depth check then was made with the small-diameter sinker bars to check for progressive hole fill. Set-down was noted at $5455 \mathrm{~m}$ ( $439 \mathrm{mbsf}$ ), so a last-minute alteration was made to change the length of the thermistor string from 445 to $435 \mathrm{~m}$. When the coring line had been recovered, the U.S.-Canadian sensor-string/data-logger assembly was lowered into the drill string. A 7-m-long geochemical fluid sampler array was attached to the kevlar sensor string, and the data logger was engaged by the overshot on the coring line for lowering to the CORK.

Normal indications of landing at the CORK were seen, but no positive indication of latch-in was noted. An overpull to about $2000 \mathrm{lb}$ would fall off to about $1000 \mathrm{lb}$ as more line was taken in. The resistance to full seating and the drag upon raising the data logger were interpreted to be the result of seal friction. Latching efforts twice resulted in sheared overshot pins, and wireline trips were made to redress the overshot. On the third wireline trip, a heavier 1700-lb sinker bar was assembled with the intention of using weight to force the seals of the data logger far enough into their seat to permit latching. There was no change in results upon engaging the data logger, however. As a precaution, the data logger and sensor string were recovered with the sinker bars for inspection. There was no visible damage to either the data-logger body or the kevlar line. Before the assembly was run back to the CORK, the lower set of seals (which had no function in the current application) were ground away with the intent of reducing resistance to insertion.

Upon landing, the familiar pattern of overpull followed by slippage again was experienced. As a final measure, 200-gpm pump circulation was tried in an effort to apply additional force down on the data logger. The measure apparently was effective, as the data logger held firm against a 3000$\mathrm{lb}$ overpull. Several minutes then was spent in working and jarring the sinker bars to shear the overshot pin and gain release from the data logger. When release had been achieved, the sinker bars were recovered--only to reveal that the data logger and thermistor string were still attached. The kevlar line and conductors of the sensor string now were damaged seriously, apparently as a result of being pinched between the data logger and its seat.

Operating time was expiring rapidly, and chances for completing the CORK installation successfully were fading. The damage to the uppermost part of the sensor string suggested that slack in the buoyant line had become fouled in the latch/seal area. Before another sensor string could be tailored to hole depth, the coring line again was reheaded for the slim sinker bars, and the 
Leg 156

Preliminary Report

Page 66

bars were run into the hole. They came to rest at the same depth as on the previous run, indicating that fill in the hole had not been the problem with landing the logger.

In a frenzy of activity, a large group of technicians, scientists, and crew unpacked and modified a 715-m sensor array, folding and lashing the kevlar cable (Fig. 2 and Table 4). The new array and data logger were run to the CORK and landed. As before, there was no positive indication of latching--only the temporary "sticking." No time remained for protracted latching efforts, so the sinker bars were "worked" only a few times before the wireline was recovered. The anticipated task of laying down and repacking the thermistor string proved to be unnecessary, as the overshot cleared the top of the pipe without the data logger attached. Despite the uncertainty of latching, there was little choice but to proceed with setting the CORK and ending the leg.

When the drill string had been lowered to land the CORK in the base of the reentry cone, the actuating ball was pumped down to effect final latch-in of the CORK assembly. Pressure was held upon landing of the ball until the latch ring was hydraulically extended into its mating groove in the 10-3/4" casing hanger. Latching was verified by taking tension on the drill string. During the pumping and latching operation, the ROV landing platform had been dropped through the moonpool and allowed to free-fall down the pipe.

Insufficient operating time remained to deploy the VIT and observe the platform and the unlatching operation. As soon as sufficient time had been allowed for the platform to land, the drill string was slacked and turned slightly to unjay the running tool from the CORK. The string was pulled free at 1100 on 23 July.

Because of the operational setbacks, some end-of-leg maintenance activities had been canceled, so only the pipe trip remained before the vessel could depart for Barbados. During the trip, both positioning beacons for Site 949 were recovered, the vessel was offset in DP mode to site NBR-1, and that beacon was activated and recovered. The drilling assembly was on board at 1900 , and JOIDES Resolution was under way at 1915 EST. 
Leg 156

Preliminary Report

Page 67

\section{Site 949 to Barbados}

We departed from the site $4 \mathrm{hr}$ behind schedule but with a short transit to Barbados. Rapid transit was aided by moderate sea conditions, light trade winds from abaft the beam, and shallow draft. An excellent average speed of 10.6 kts was made good, and the first mooring line was put over in Bridgetown Harbor at $1000 \mathrm{hr}$ on 24 July, ending Leg 156. 


\section{OCEAN DRILLING PROGRAM \\ OPERATIONS RESUME \\ LEG 156}

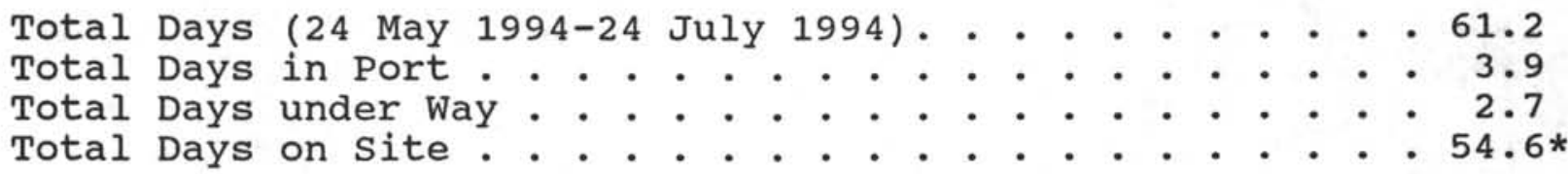

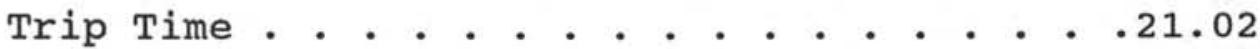

Coring Time... . . . . . . . . . . 4.21

Drilling Time . . . . . . . . . . . . 2.31

Logging/Downhole Science Time . . . . . . .12.22

Reentry \& Related Time. . . . . . . . . 2.44

Casing \& cementing time . . . . . . . 6.50

Stuck Pipe and Hole Trouble Time. . . . . 2.68

Fishing \& Remedial Time . . . . . . . . 1.13

Mechanical Downtime (Contractor). . . . . 0.10

Mechanical Downtime (ODP) . . . . . . 1.32

other................. 0.65

Total Distance Traveled (nautical miles) . . . . . . . . 652

Average Speed (knots). . . . . . . . . . . . . . . 10.6

Number of Sites. . . . . . . . . . . . . . . . . . 3

Number of Holes. . . . . . . . . . . . . . . . . . . 8

Number of Reentries. . . . . . . . . . . . . . . . . .23*

Total Interval Cored (m) . . . . . . . . . . . . . 468.6

Total Core Recovery $(\mathrm{m})$. . . . . . . . . . . . . . . . 267.1

Percent Core Recovery. . . . . . . . . . . . . . . . . .57.0

Total Interval Drilled (m) . . . . . . . . . . . . . 2862.0

Total Penetration (m). . . . . . . . . . . . . . . . . . . . . . . . 6

Maximum Penetration (m). . . . . . . . . . . . 5920

Maximum Water Depth (m from drilling datum). . . . . . .5024 .0

Minimum Water Depth (m from drilling datum). . . . . . .4891.0

*believed to be DSDP/ODP record 


\section{SITE SUMMARY}

\section{LEG 156}

\begin{tabular}{|c|c|c|c|c|c|c|c|c|c|c|c|}
\hline HOLE & LATITUDE & LONGITUDE & $\begin{array}{l}\text { WATER } \\
\text { DEPTH } \\
\text { (meters) }\end{array}$ & $\begin{array}{l}\text { NUMBER } \\
\text { OF CORES }\end{array}$ & $\begin{array}{l}\text { INTERVAL } \\
\text { CORED } \\
\text { (meters) }\end{array}$ & $\begin{array}{l}\text { CORE } \\
\text { RECOVERED } \\
\text { (meters) }\end{array}$ & $\begin{array}{l}\text { PERCENT } \\
\text { RECOVERED } \\
\text { (percent) }\end{array}$ & $\begin{array}{l}\text { DRILLED } \\
\text { (meters) }\end{array}$ & $\begin{array}{l}\text { TOTAL } \\
\text { PENETRATION } \\
\text { (meters) }\end{array}$ & $\begin{array}{l}\text { TIME } \\
\text { ON HOLE } \\
\text { (hours) }\end{array}$ & $\begin{array}{l}\text { TIME } \\
\text { ON SITE } \\
\text { (days) }\end{array}$ \\
\hline \multirow[t]{2}{*}{$947 A$} & $1531.48^{\prime} \mathrm{N}$ & $5844.88^{\prime} \mathrm{W}$ & 4891.0 & 0 & 0 & 0 & NA & 583.7 & 583.7 & 49.25 & \\
\hline & & & SITE TOTALS: & 0 & 0 & 0 & NA & 583.7 & 583.7 & 49.25 & 2.1 \\
\hline \multirow[t]{2}{*}{$\begin{array}{l}948 A \\
948 B \\
948 C \\
948 D\end{array}$} & $\begin{array}{l}1531.56 \mathrm{~N} \\
1531.46 \mathrm{~N} \\
1531.57 \mathrm{~N} \\
1531.46^{\prime} \mathrm{N}\end{array}$ & $\begin{array}{l}5843.94 \mathrm{~W} \\
5843.94^{\prime} \mathrm{W} \\
5843.94^{\prime} \mathrm{W} \\
5843.91^{\prime} \mathrm{W}\end{array}$ & $\begin{array}{l}4940.0 \\
4949.0 \\
4942.5 \\
4949.0\end{array}$ & $\begin{array}{c}0 \\
1 \\
20 \\
0\end{array}$ & $\begin{array}{c}0 \\
4.0 \\
180.7 \\
0\end{array}$ & $\begin{array}{c}0 \\
3.7 \\
171.5 \\
0\end{array}$ & $\begin{array}{c}\text { NA } \\
92.8 \% \\
94.9 \% \\
\text { NA }\end{array}$ & $\begin{array}{c}583.7 \\
45.0 \\
411.3 \\
538.0\end{array}$ & $\begin{array}{c}583.7 \\
49.0 \\
592.0 \\
538.0\end{array}$ & $\begin{array}{c}47.75 \\
15.00 \\
127.00 \\
492.00\end{array}$ & \\
\hline & & & SITE TOTALS: & 21 & 184.7 & 175.2 & $94.9 \%$ & 1578.0 & 1762.7 & 681.75 & 28.4 \\
\hline \multirow[t]{3}{*}{$\begin{array}{l}949 A \\
949 B \\
949 C\end{array}$} & $\begin{array}{l}1532.22 \mathrm{~N} \\
1532.16^{\prime} \mathrm{N} \\
1532.21^{\prime} \mathrm{N}\end{array}$ & $\begin{array}{l}5842.86^{\prime} \mathrm{W} \\
5842.85^{\prime} \mathrm{W} \\
5842.6^{\prime} \mathrm{W}\end{array}$ & $\begin{array}{l}5020.5 \\
5024.0 \\
5016.0\end{array}$ & $\begin{array}{c}1 \\
25 \\
7\end{array}$ & $\begin{array}{c}3.0 \\
218.1 \\
62.8\end{array}$ & $\begin{array}{c}3.0 \\
86.8 \\
2.2\end{array}$ & $\begin{array}{l}98.3 \% \\
39.8 \% \\
3.5 \%\end{array}$ & $\begin{array}{c}53.2 \\
246.1 \\
401.0\end{array}$ & $\begin{array}{c}56.2 \\
464.2 \\
463.8\end{array}$ & $\begin{array}{c}11.50 \\
77.25 \\
490.00\end{array}$ & \\
\hline & & & SITE TOTALS: & 33 & 283.9 & 91.9 & $32.4 \%$ & 700.3 & 984.2 & 578.75 & 24.1 \\
\hline & & & LEG TOTALS: & 54 & 468.6 & 267.1 & $57.0 \%$ & 2862.0 & 3330.6 & 1309.75 & 54.6 \\
\hline
\end{tabular}


Leg 156

Preliminary Report

Page 70

Table 3

Configuration of French-designed (IFREMER) sensor string deployed in Hole 948D.

\begin{tabular}{rc}
\hline $\begin{array}{r}\text { Depth } \\
\text { (mbsf) }\end{array}$ & $\begin{array}{c}\text { Component } \\
\text { type } \mathrm{a}\end{array}$ \\
\hline 8.4 & TP \\
58.5 & TT \\
108.5 & TT \\
158.6 & TT \\
208.6 & TT \\
258.7 & TT \\
308.8 & TT \\
358.8 & TT \\
388.8 & TT \\
398.8 & TT \\
418.8 & TT \\
438.8 & TT \\
448.8 & TT \\
458.8 & TT \\
468.8 & TT \\
473.7 & TT \\
478.8 & TP \\
483.8 & TT \\
488.7 & TT \\
508.8 & TP \\
513.8 & SB \\
& \\
\hline & \\
47.8 &
\end{tabular}

a TT: two temperature sensors;

TP: one temperature and one pressure sensor;

SB: sinker bar 
Leg 156

Preliminary Report

Page 71

Table 4

Final thermistor locations of U.S.-Canadian-designed string in Hole 949C.

\begin{tabular}{cc}
\hline $\begin{array}{c}\text { Thermistor } \\
\text { number a }\end{array}$ & $\begin{array}{c}\text { Depth b } \\
\text { (mbsf) }\end{array}$ \\
\hline 1 & 200.4 \\
4 & 279.5 \\
5 & 299.4 \\
6 & 319.0 \\
3 & 327.1 \\
7 & 338.7 \\
8 & 358.5 \\
9 & 377.6 \\
2 & 398.4 \\
10 & 407.9 \\
\hline
\end{tabular}

a Thermistor numbering is based on original string configuration.

b Depths are based on the assumption that the base of the CORK data logger is at $1.0 \mathrm{mbsf}$. 


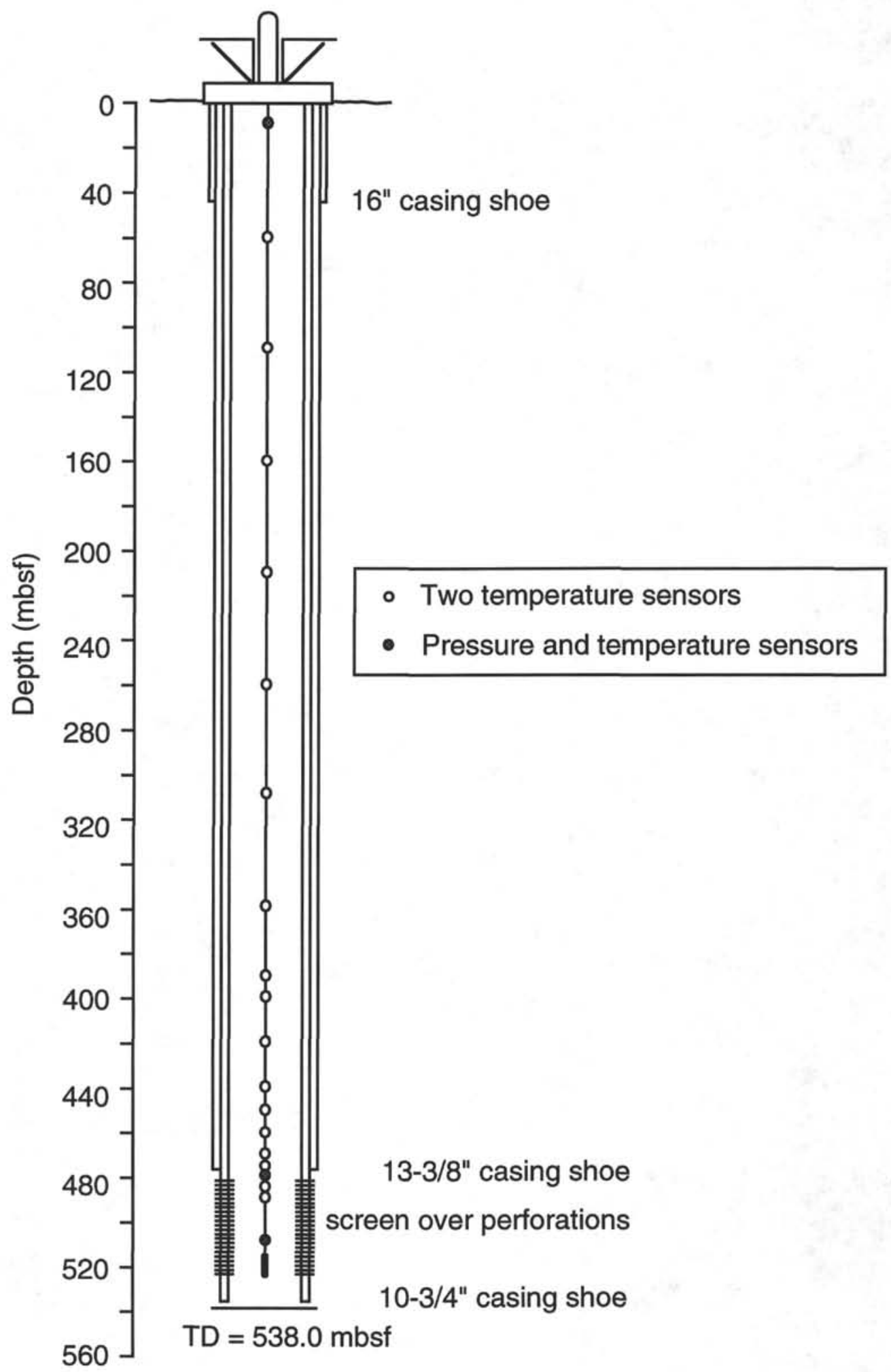

Figure 1. Final configuration of French-designed (IFREMER) sensor string, casing, and screen, deployed as part of a long-term borehole observatory (CORK) in Hole 948D. 


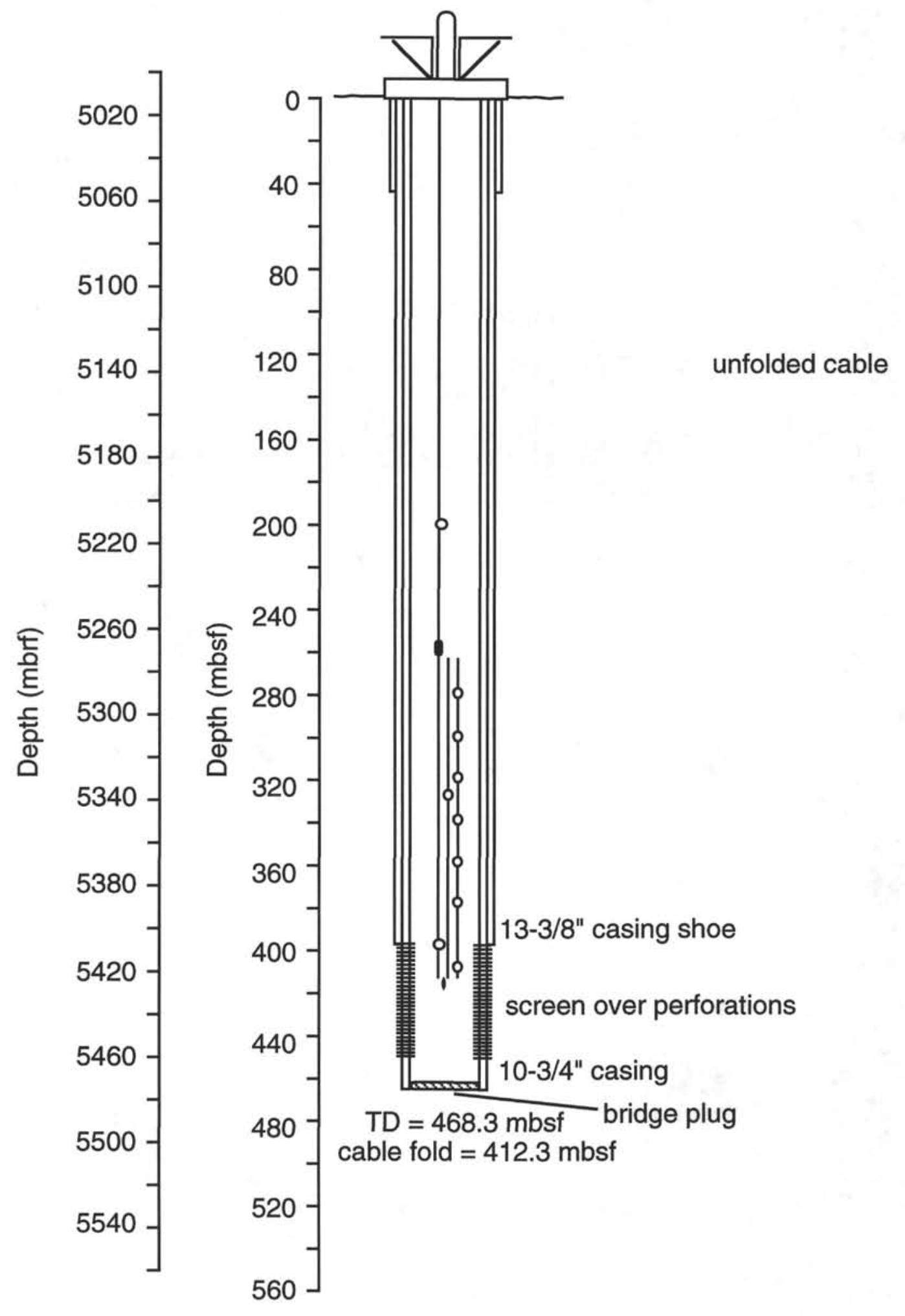

Figure 2. Schematic of final U.S.-Canadian-designed sensor string in Hole 949C. The original, unfolded geometry is shown for reference. As illustrated, the string was folded twice to shorten it and place two thermistors in the screened interval. Thermistor locations are indicated with open circles. The location of the osmotic fluid sampler is indicated with a filled oval. 
TECHNICAL REPORT 
Leg 156

Preliminary Report

Page 76

ODP Technical and Logistics personnel aboard JOIDES Resolution, Leg 156:

Lab Officer:

Burney Hamlin

Marine Lab Specialist (X-ray):

Mary Ann Cusimano

Marine Lab Specialist (Photography):

Roy Davis

Marine Lab Specialist (Storekeeper):

John Dyke

Marine Computer Specialist:

Edwin Garrett

Assistant Lab Officer (U/W Lab):

Dennis Graham

Marine Lab Specialist (Thin Section):

"Gus" Gustafson

Marine Lab Specialist (Yeoperson):

Michiko Hitchcox

Marine Computer Specialist:

Bryan Ignatow

Marine Lab Specialist (Paleomagnetics):

Kris Kristofferson

Marine Lab Specialist:

Greg Lovelace

Marine Electronics Specialist:

Eric Meissner

Marine Electronics Specialist

Dwight Mossman

Marine Lab Specialist (Chemistry):

Chieh Peng

Marine Lab Specialist (Chemistry):

Phil Rumford

Marine Lab Specialist (X-ray):

Don Sims

Marine Lab Specialist (Curatorial):

Lorraine Southey 
Leg 156

Preliminary Report

Page 77

\section{PORT CALL}

Leg 156 began on 24 May in Bridgetown, Barbados. A magazine and a frame required to store the explosives for the bottom-shot shear-wave experiment were installed by an ABS-licensed welder. The 600 boxes of cores collected during Leg 155 were transferred to refrigerated containers. The logging-while-drilling (LWD) leased logging tools were loaded on board.

A technical-service person from Philips Electronic Instruments installed a new high voltage connector and a new tube shield insulator sheet, and replaced burnt wiring around a terminal strip.

Seven pallets of air freight were not delivered prior to sailing time.

\section{UNDER WAY}

The JOIDES Resolution sailed at 22:50 EST on 27 May for Site 947, northeast of Barbados. Navigation tapes were made for the transit to the drilling area. We arrived on site on 29 May to begin the LWD experiment.

Concluding LWD operations on 2 June, the ship was again under way to Bridgetown to return the leased tools and pick up the missing air freight. The ship arrived on 3 June, and the LWD tools were unloaded. The missing seven pallets of air freight were loaded. The Barbados Defense Group delivered the explosives that were sent to support the University of Birmingham's bottom-shot shear-wave experiment. With the explosives safely stored in the new magazine, the ship departed for the drilling area.

Underway watches were manned to collect depth and magnetometer information both enroute to port and back to the drilling area. No seismic work was done because of the great extent of previous seismic work in the region.

Four helicopter rendezvous were completed to the drilling sites during the course of the cruise; one flight was made for personal reasons, and three other flights, to exchange scientists, personnel, and drilling equipment. 
Leg 156

Preliminary Report

Page 78

Drilling operations were completed on 23 July and the ship returned to Barbados.

\section{OBJECTIVES}

Leg 156 constituted a drilling and experimental program to evaluate the characteristics of fluid flow in an accretionary-prism environment. Three sites were occupied (Sites 947-949). The area had been visited previously, most recently on ODP Leg 110 . This permitted LWD operations prior to coring during the first week. The LWD logging system was necessary because hole instability had prevented wireline logging on the previous legs. Two LWD holes (Holes 947A and 948A), one which successfully penetrated across the décollement zone, were drilled and logged.

Operations produced two cased reentry holes with screened sections that accommodated packer experiments. The reentry cones were CORKed, instrumented, and outfitted for future submersible visits.

\section{CURATION}

A detailed sample strategy was prepared during the first week. Sampling density in the recovered core material was great. Cores were available in the lab at the request of the scientific party for extensive blocks of time. Over-sampling, desiccation, and contamination were constant concerns of the curator. An unusual number of whole-round samples were taken for shore analysis to support geochemical, permeability, structural, and deformation studies. "Cluster sampling" strategies will allow for integrated physical properties, grain size, and X-ray measurements from adjacent samples.

Because of low recovery, the cores will not be unloaded until after Leg 157. 
Leg 156

Preliminary Report

Page 79

\section{LABORATORIES}

\section{Core Lab}

Suitable cores were measured with the MST; mechanical problems with the instrument were minimal. Selected sections were counted in the natural gamma sensor for $4 \mathrm{hr}$ to evaluate whether potassium, thorium, and uranium peaks could be determined with accuracy and quantitatively. The use of other physical properties tools was routine.

Staffing the paleomagnetics lab this leg was Kris Kristofferson, an employee of 2G, the company that made our cryogenic magnetometer. Kris and our electronic technician (ET) made some progress in reducing the flux jump instances that occur each day, and they initiated repairs on worn or potentially troublesome areas.

No downhole orientation tools were required this leg.

\section{Chemistry Lab}

Much of the scientific support for this leg was provided by the analysis of interstitial squeeze water samples and of gas collected from the cores before they were cut or from headspace samples. Instrument and volumetric calibrations and fresh standards were made to assure precision results. Extended use of the Carver presses resulted in some oil leaks and a fleeting need for the installation of one of the spare presses.

\section{X-ray Lab}

X-ray-diffraction samples were analyzed to determine both the background mineralogy of the cored material and the mineralogy of specific veins and alteration zones. Standard mineral mixtures were prepared covering three sediment groups. These standards and some Philips software routines let the investigators calculate some quantitive values for the bulk mineralogy scans. A second PC was installed in the lab to allow an investigator to review scans and to use the plotter and printer while data were being collected on the other PC. 
Leg 156

Preliminary Report

Page 80

\section{Paleo Lab}

The area was utilized fully by two paleontologists; few problems were noted. A heat buildup at the hoods was noticed, and the situation was traced to a damper in the lab stack stairwell that controls make-up air to the hoods. It had been mistakenly adjusted to full open.

\section{COMPUTER SERVICES}

No serious breakdowns occurred, and no major changes were made to hardware or software. Recommendations included (1) upgrading the remaining 286 and 386 PCs with 486 motherboards for the benefits gained with new processors and for consistency; (2) replacing the small hard drives in the older Macintoshes, if not replacing the slower discontinued IIx and SI models, as recent applications are large and require speed and ample hard-disk space; and (3) replacing some of the laser printers, as many have approached or exceeded their design life. A consolidated effort to effect these replacements will be initiated ashore.

Participants bringing their own SUN workstations were able to integrate them into the present network.

\section{MICROSCOPES}

A JVC video camera and video capture system were installed for the investigators' use. The microscope objectives were marked with inventory numbers. A SUN station with dual monitors was moved into the microscope area to process VSP data collected during the cruise. Also accommodated was the microfiche reader from the library. Displaced equipment was stored in the lab or moved for use elsewhere.

\section{ELECTRONICS SUPPORT}

The copy machines were serviced twice this leg, and following comments from a recent Lab Working Group Overview committee meeting, their future working life has been assessed. The feeling is that they can be kept serviceable for another year. 
WSTP downhole-temperature measurements were successful. Only one run was noisy. Experimentation with ONSET recorders, which were run in parallel with the DCLD recorders on a few runs, was encouraging.

Many of the small black and white rig-floor video monitors throughout the labs were checked, and components mixed, replaced, and aligned, resulting in considerable picture improvement.

Another ONSET computer was used successfully to interface navigation header data to the SUN, circumventing the MASSCOMP computer presently used.

The timers for the bottom-shot shear-wave explosives were tested and then set when the experiment was conducted.

\section{SPECIAL PROJECTS}

\section{Doppler Sonar}

A request was made to clear a hole in the transducer housing that would allow accumulated air to escape; trapped air can degrade the instrument's performance. The stem and housing were pulled, and a hole cleared. The stem movement resulted in top plate O-ring failure and an accumulation of several inches of water in the space before running off to the bilge. In addition, the stem connector was damaged and replaced. We were unable to locate drawings or notes pertinent to our customized top assembly, showing details of the stem or of the O-rings and their Parker numbers. A request to ODP for information and a description of the problem resulted in the revelation that the stem was installed upside down. The connector was replaced, and the stem was rotated in the gym. An attempt to align the unit was made under way to Barbados. A maintenance guide was prepared.

\section{Bilge Drain}

The accumulation of water that could not be pumped out led to a request to inspect the casing hold drains, which are covered by planking, decking, and our bulk paper products. The area was cleared to make the drain accessible. The drain was immaculately clean, and blocked strainers elsewhere were cleared. The area was inspected by the SEDCO Chief Engineer, and the decking replaced. 
Leg 156

Preliminary Report

Page 82

\section{Vertical Seismic Profiling (VSP)}

Several VSP experiments were conducted using two BOLT 1500 air guns, one of them provided by the investigator. The dual gun array was deployed from the crane boom and was satisfactorily floated by a large foam float, used for the first time. Although noise from loose pipe and thrusters was noted, the data were good. One aft trailing far-field hydrophone, deployed through a sheave on the crane boom, was lost at night when currents swept it into the screws or thrusters.

\section{Shear-Wave VSP}

The many hours of planning to include a bottom-shot shear-wave VSP experiment on Leg 156 resulted in successful acquisition of the desired data. The Gaitronics communications link was extended to the fantail work area so that a noise-canceling headset could be used there. Deployment of the timed explosives by maneuvering the ship over the selected stations, then returning for the reentry, and emplacing the recording tool in the reentry hole went very smoothly. The insistence that the shots be deployed during daylight hours resulted in some blocks of time/operations being shifted for accommodation. The subsequent recording of the shots also went well. Eighteen successful recordings, two misfires, and one return missed because of a telemetering error still were considered an exceptional accomplishment. The number of shots recorded and the exceptional $32 \mathrm{~s}$ length of the 15 channels of information from the geophone array will take considerable time and perhaps some software modification before the data are reduced.

The captain opted to keep the radar on at night, as there was occasional traffic in the area. The topic of how the radar could interfere with the shot preparation was raised during pre-deployment meetings, as it is 300 feet away and blocked by the derrick. Using lookouts or noncontinuous radar operation was not considered.

\section{Mechanical Continuous Sampler (MCS)}

In conjunction with the deployment of the U.S.-Canadian-designed (Becker/Davis) thermistor string at Site 949 was the concurrent deployment of the Mechanical Continuous Sampler (MCS), an osmotic-powered fluid sampler from Scripps Institution of Oceanography. Assistance was given to the investigator to check the experimental device and to deploy it on the thermistor string. The sampler is driven by a concentrated salt solution and is designed to sample borehole fluids at 
Leg 156

Preliminary Report

Page 83

the rate of $40 \mathrm{~mL} / y e a r$ at $25^{\circ} \mathrm{C}$. The collected water will be analyzed to monitor the return of the borehole water to equilibrium. It will be retrieved in 2 years with the thermistor string. Notes were made to assist those involved in future deployments.

\section{SAFETY}

One of the scientists lost control of a core-lab door handle, resulting in a broken finger. The design of the door-latching mechanisms on these weatherproof doors leads to eventual loosening of the action until it is able to fall abruptly if released. Tightening the mechanism too much makes the doors difficult to operate; the fine line is not routinely maintained. Other injuries were minor.

\section{PROBLEMS}

The quality of the picture from the new rig-floor camera is unremarkable, with low contrast and differential focus. Rerouting signal cables has reduced the jittering, and other adjustments have improved the picture quality. Few of the monitors and receivers could handle the low signal output to deliver a normal-looking picture; in fact, the video distribution amplifiers are boosting the signal to near the indicated top of their range. The lens focal length selection is too long, with logging or core-barrel activity out of view.

We accommodated two SUN workstations, each supporting dual monitors. As one of the investigator's monitors failed in shipment, it was necessary to utilize the Computer-user Room SUN station and its monitor. This displaced the Mac color scanner/CD-ROM hardware to the back of the Computer-User Room, compounding the congestion in the area where three Mac systems, a PC, and the AV TV/VCR are located.

Weekend computer communication seemed flawed much of the leg, with some aspect of the system down. Email users reported lost communications as segments of personal serial traffic seemed to disappear, although the shore-ship traffic seemed to be accounted for. Message distribution by size was canceled, and new shore software was tested. A shore software modification will be proposed to help eliminate lost traffic. 
Leg 156

Preliminary Report

Page 84

Table 1. Leg 156 Laboratory Statistics.

GENERAL

Sites: $\quad 3$

Holes: $\quad 8$

Meters drilled: $\quad 2866.5$

Meters cored: $\quad 468.6$

Meters recovered: $\quad 267.1$

Time on site (days): $\quad 54.6$

Number of cores : $\quad 54$

Number of samples: $\quad 3339$

Number of core boxes: $\quad 42$

DOWNHOLE TOOLS

WSTP-HF: $\quad 10$

ANALYSIS

Magnetics Lab

Half-section measurements : $\quad 177$

Discrete measurements: $\quad 436$

Kappabridge: $\quad 288$

Physical Properties

Index properties: $\quad 395$

Velocity: $\quad 678$

Resistivity: $\quad 453$

Therm con: $\quad 86$

MST: $\quad 328$

Shear strength: $\quad 22$

Chemistry Lab

Inorganic carbonates $\left(\mathrm{CaCO}_{3}\right)$ : $\quad 505$

Water chemistry (including: $\mathrm{pH}$, alkalinity, sulfate, calcium, magnesium, chlorinity, potassium, silica, lithium): $\quad 44$

Headspace gas analysis: $\quad 66$

Natural gas analyzer: $\quad 90$

Pyrolysis evaluation :

GHM 15

Rock-Eval $\quad 66$

X-ray Lab

XRD: $\quad 500$

THIN SECTIONS: 2

UNDERWAY GEOPHYSICS

Total transit, nautical miles: $\quad 656$

Bathymetry: $\quad 300$

Magnetics: $\quad 300$

XBTs used: $\quad 12$ 